\title{
Simulation of the Tropical Pacific Climate with a Coupled Ocean-Atmosphere General Circulation Model. Part II: Interannual Variability
}

\author{
A. W. RobertSON, ${ }^{*}$ C.-C. MA, M. GHIL, ${ }^{*}$ AND C. R. MeCHOSO \\ Department of Atmospheric Sciences, University of California, Los Angeles, Los Angeles, California
}

(Manuscript received 22 September 1993, in final form 15 June 1994)

ABSTRACT

\begin{abstract}
Two multiyear simulations with a coupled ocean-atmosphere general circulation model (GCM)-totaling 45 years-are used to investigate interannual variability at the equator. The model consists of the UCLA global atmospheric GCM coupled to the GFDL oceanic GCM, dynamically active over the tropical Pacific. Multichannel singular spectrum analysis along the equator identifies ENSO-like quasi-biennial (QB) and quasi-quadrennial (QQ) modes. Both consist of predominantly standing oscillations in sea surface temperature and zonal wind stress that peak in the central or east Pacific, accompanied by an oscillation in equatorial thermocline depth that is characterized by a phase shift of about $90^{\circ}$ across the basin, with west leading east. Simulated interannual variability is weaker than observed in both simulations. One of these is dominated by the $Q B$, the other by the QQ mode, although the two differ only in details of the surface-layer parameterizations.
\end{abstract}

\section{Introduction}

In Part I of this two-part paper (Robertson et al. 1995), we analyzed the mean climate and seasonal cycle over the tropical Pacific in an 11-year simulation with the University of California, Los Angeles coupled ocean-atmosphere general circulation model (GCM). Part II presents a detailed analysis of the model's interannual variability at the equator in a preceding 11 -year simulation (decade I, hereafter) and then in the simulation considered in Part I (decade II, hereafter). Finally, we analyze a 26 -year extension to decade II that was performed to corroborate the variability occurring in the latter.

The model consists of a global atmospheric GCM (AGCM) coupled to an oceanic GCM (OGCM) of the Pacific Ocean in the latitudinal band $30^{\circ} \mathrm{S}-50^{\circ} \mathrm{N}$. Climatological time-varying land-sea surface conditions are prescribed elsewhere. In the first simulation (decade I), the heat and momentum fluxes computed using the planetary boundary layer (PBL) parameterization in the AGCM were modified in two important aspects. 1) The transfer coefficients of heat and moisture were computed using a wind speed of $5 \mathrm{~m} \mathrm{~s}^{-1}$ whenever the wind speed in the PBL falls below this value. 2) A parameterization of the penetration of solar radiation

\footnotetext{
* Also at Institute of Geophysics and Planetary Physics, University of California, Los Angeles, Los Angeles, CA.
}

Corresponding author address: Dr. Andrew W. Robertson, Department of Atmospheric Sciences, University of California at Los Angeles, 405 Hilgard Avenue, Los Angeles, CA 90095-1565. into the ocean was included. The two modifications were motivated by current ideas on the heat transfer between the atmosphere and the ocean in regions of low surface wind speeds and on ocean turbidity, respectively. The first 11-year simulation, however, shows an equatorial cold bias. At this point, the modifications to the treatment of the surface heat fluxes at low wind speeds and the penetration of solar radiation into the ocean were removed. The model was then restarted at year 9 and run for a further 11 years of integration, constituting the second simulation (decade II), whose seasonal cycle is discussed in Part I. Minor but significant improvements to the seasonal cycle did result from these changes. There are also differences in the character of interannual variability between the two decades, as will be shown below.

Recent years have seen great advances in our understanding of interannual variability in the tropical Pacific region and El Niño/Southern Oscillation (ENSO). These advances have occurred largely by a linear analysis of coupled ocean-atmosphere oscillatory modes (Hirst 1986; Battisti and Hirst 1989; Neelin 1991). In a broader nonlinear perspective, the success of linear analysis at capturing important features of observed variability is likely to be due to the proximity in parameter space between the first oscillatory bifurcation and the actual point at which the natural system operates (Neelin et al. 1994). In this spirit, we apply the multichannel singular spectrum analysis (M-SSA) used in Part I. Single-channel SSA (Ghil and Vautard 1991; Vautard et al. 1992) and M-SSA (Keppenne and Ghil 1992) have been shown to extract near periodicities, and their associated spatiotemporal structures, 
from short noisy time series. The oscillatory structures found by M-SSA resemble the eigenmodes of simple coupled models enough to justify a dynamical interpretation.

The coupled GCM (CGCM) is discussed in detail in Part I; the model configurations of the two simulations are summarized here in section 2 . Section 3 presents a conventional analysis of the interannual variability (with respect to the mean seasonal cycle) in terms of standard anomaly indices and Hovmoeller diagrams. As in Part I, the mean seasonal cycle is defined by long-term averages of each month. We then discuss the M-SSA results in section 4 . The conclusions of Part II follow in section 5.

\section{The model configurations}

The atmospheric and oceanic components of our coupled model are each capable of simulating the main features associated with ENSO when forced by the appropriate observed boundary conditions. The AGCM underestimates, however, the magnitude of the surface wind stress at the equator, both in the time mean and during ENSO episodes.

For the first simulation (decade I), the model was initialized by taking the atmospheric state on $15 \mathrm{Jan}$ uary after 3 years of uncoupled integration of the AGCM with a prescribed and time-varying distribution of sea surface temperature (SST) corresponding to an observed climatology. The ocean is taken to be at rest, with temperature and salinity distributions taken from the observed January climatology (Levitus 1982). The primary spinup of the ocean takes place within the first 6-8 months of integration. The coupled model was run for 11 years, of which the last 10 (years 2-11) are used in the analysis of decade I. During this first simulation, solar radiation penetration into the ocean is parameterized according to the exponential formulation of Paulson and Simpson (1977). In addition, the transfer coefficients of heat and moisture (at the ocean surface) are computed using a wind speed of $5 \mathrm{~m} \mathrm{~s}^{-1}$ whenever the wind in the PBL drops below this value. (The current value of the wind is still used to compute the friction velocity.)

The model was then restarted on 15 April of year 9 of the first coupled integration with these two parameterization modifications removed; that is, without modification to the AGCM's parameterizations of the surface fluxes and without solar penetration past the topmost ocean layer $(10 \mathrm{~m})$. The restarted model was run for a further 134.5 months, of which the latter 11 years are used in the analysis of decade II (thus neglecting a 2.5 -month initial adjustment period). The seasonal cycle of this second simulation is described in Part $\mathrm{I}$.

The mean states and seasonal cycles of the two simulations do not differ greatly. Figure 1 shows the mean seasonal cycle at the equator in decade I for SST and the zonal wind stress. By comparison, decade II (see Figs. 6 and 7 of part I) has a stronger zonal gradient of SST at the equator, with the cold tongue being more intense and longer lived and the extreme west Pacific being warmer. This is associated with slightly stronger mean equatorial wind stress. In all, the mean state and seasonal cycle are somewhat more realistic in decade II.

\section{Conventional indices}

In this section we analyze deviations from the mean seasonal cycle at the equator in terms of Hovmoeller diagrams and conventional indices. Figure $2 \mathrm{a}$ shows the time evolution of the SST at the equator in decade I at the resolution of the OGCM ( $1^{\circ}$ in longitude). The strong seasonal cold tongue in the east Pacific dominates the figure. There is no noticeable trend in SST at the western side of the basin, although the equatorial east Pacific does cool slightly over time. We recall that no surface "flux correction" is applied to the model, whose climate state is consequently free to drift. Figure $2 b$ shows the evolution with the mean seasonal cycle removed. Here, and in all subsequent treatment of the SST anomalies, we use the lower resolution of the AGCM ( $4^{\circ}$ lat $\times 5^{\circ}$ long), averaging from $4^{\circ} \mathrm{S}$ to $4^{\circ} \mathrm{N}$. In addition, Fig. $2 \mathrm{~b}$ has been detrended and lowpass filtered with an 11-point Gaussian filter that yields a half-power period of about 10 months. SST anomalies are confined mostly to the east of the basin, peaking around $120^{\circ} \mathrm{W}$, with amplitudes of about $0.5 \mathrm{~K}$. They have roughly stationary phase and tend to appear in the latter part of the calendar year, suggesting a quasibiennial (QB) modulation in the strength and duration of the seasonal cold tongue.

We search for indication of air-sea interaction in telltale correlations between SST, zonal wind stress, and sea level pressure by plotting three conventional anomaly indices in Fig. 3. Anomalous SST is averaged over a box in the eastern equatorial Pacific $\left(130^{\circ}\right.$ $110^{\circ} \mathrm{W}, 4^{\circ} \mathrm{S}-4^{\circ} \mathrm{N}$ ), and zonal wind stress is averaged to the west of this $\left(170^{\circ}-120^{\circ} \mathrm{W}, 4^{\circ} \mathrm{S}-4^{\circ} \mathrm{N}\right)$, where the respective anomaly maxima are situated. We define the Southern Oscillation index (SOI) here as the difference in anomalous sea level pressure across the basin between $140^{\circ} \mathrm{E}, 2^{\circ} \mathrm{S}$ and $120^{\circ} \mathrm{W}, 2^{\circ} \mathrm{S}$ - two points marking the approximate centers of action of the model's Southern Oscillation (SO). The indices are not detrended, but little drift occurs over the simulation after an initial cooling. The QB variation in SST stands out between years 4 and 7 . Zonal wind-stress anomalies

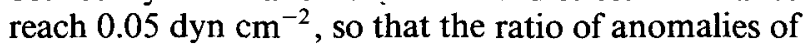
equatorial wind stress to SST is about $0.1 \mathrm{dyn} \mathrm{cm}^{-2}$ $\mathrm{K}^{-1}$. This is about half that inferred from surface wind observations (e.g., Stricherz et al. 1992) and uncoupled AGCM simulations forced by observed SSTs (e.g., Kitoh 1991). Still, anomalous wind stress (dashed) and SST ( solid) tend to be temporally in phase, with warm 
(a) SST Decade I

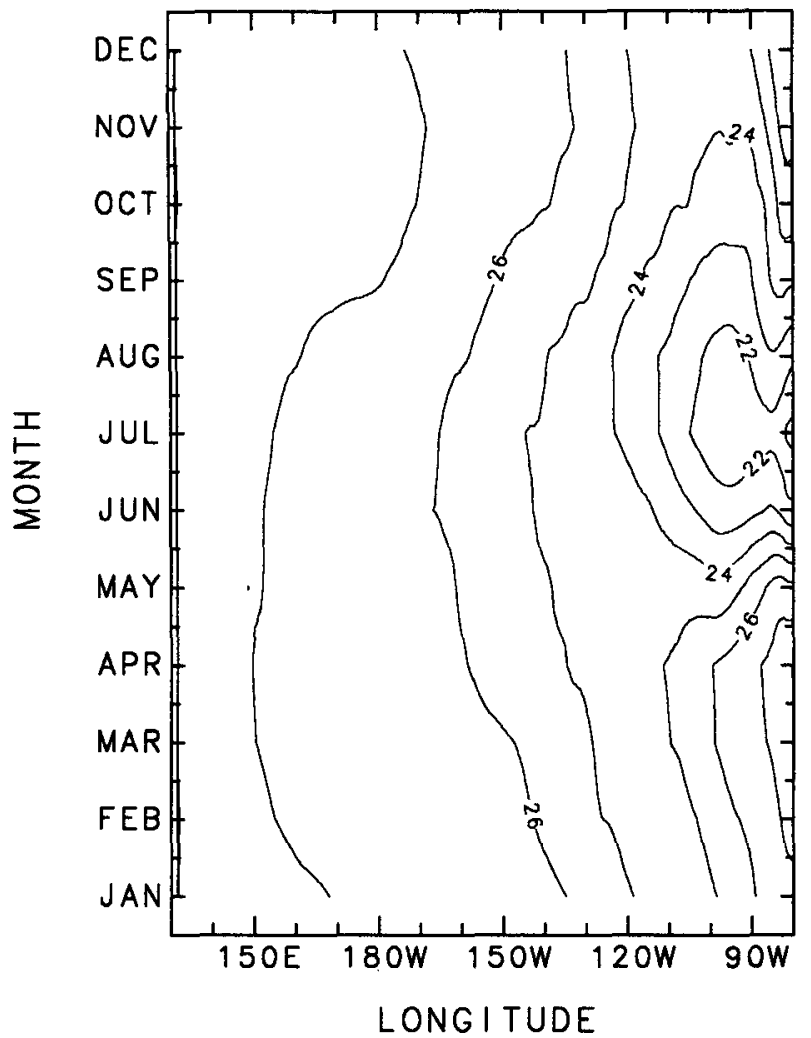

(b) $\tau_{\times}$Decade 1

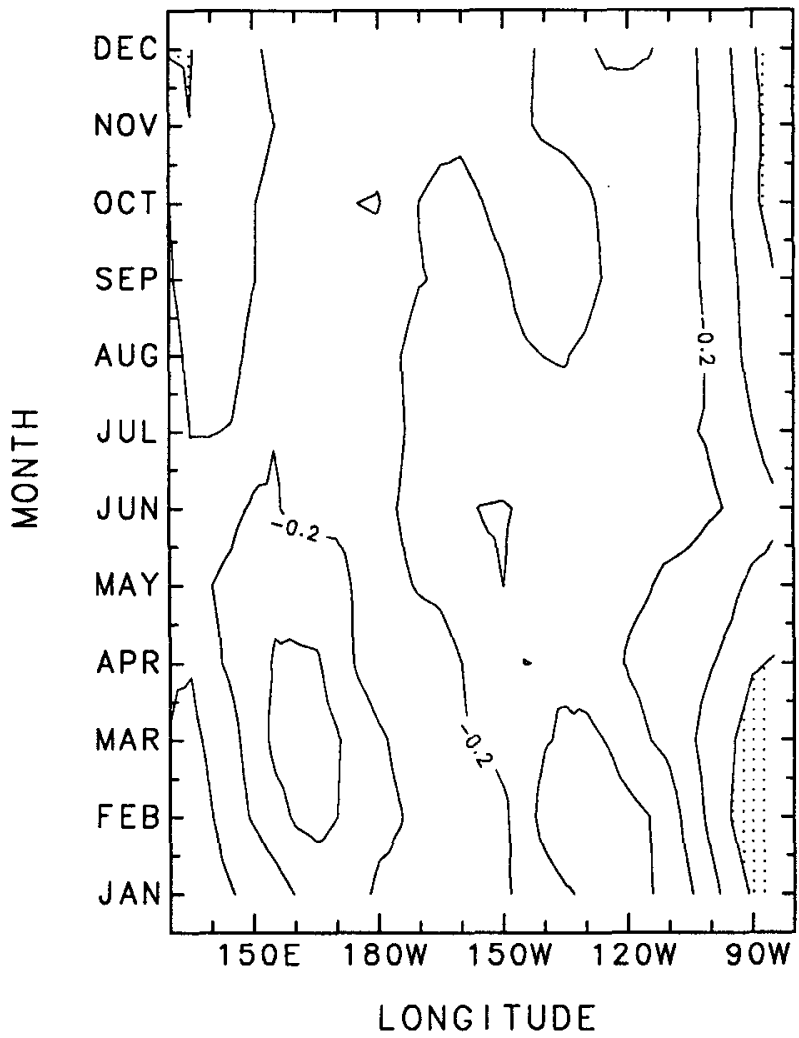

FlG. 1. The mean seasonal cycle at the equator in decade I. (a) SST (contour interval $1 \mathrm{~K}$ ) and (b) zonal wind

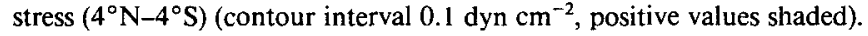

SST anomalies accompanied by westerly wind-stress anomalies, and vice versa; this synchroneity is indicative of air-sea interaction of the type first postulated by Bjerknes (1969). The SST and wind-stress indices in Fig. 3 have a correlation coefficient of 0.85 . On the basin scale, the SO exhibits a modest anticorrelation $(-0.77)$ with SST anomalies in the eastern equatorial Pacific.

We turn now to decade II, recalling that the two simulations differ in two important aspects: 1) the initial states and 2) the treatment of the surface heat fluxes at low wind speeds and of solar penetration into the ocean. These differences cause the mean state of decade II to be the more realistic, with a stronger east-west gradient of SST at the equator and stronger surface winds (see section 2). Figure 4 presents Hovmoeller diagrams of equatorial SST in decade II, together with its deviation from the mean seasonal cycle. Again, a slight cooling trend is visible in the eastern equatorial Pacific, with a concomitant increase in the zonal gradient of SST at the equator. Figure $4 b$ indicates that the largest anomalies in SST are more pronounced than those in decade I and peak toward the central Pacific around $150^{\circ} \mathrm{W}$, with amplitudes of about $0.75 \mathrm{~K}$. Their phase is roughly stationary or slightly westward propagating, and they tend to appear in the latter part of the calendar year. Anomaly indices for decade II similar to those in Fig. 3 are plotted in Fig. 5, averaging both SST and wind stress now over a box in the central equatorial Pacific $\left(160^{\circ}-140^{\circ} \mathrm{W}\right.$, $4^{\circ} \mathrm{S}-4^{\circ} \mathrm{N}$ ), where the respective anomaly maxima are situated. A marked equatorial cooling takes place during the first 2 years of simulation, as the coupled system adjusts to the initial imbalance created by the parameterization modifications. This equatorial cooling trend, which may not be complete by the end of the simulation, appears to be an adjustment rather than a model drift, since the SST averaged over the entire ocean model domain cools by less than $0.1 \mathrm{~K}$ over the same interval. Zonal wind-stress anomalies over the same region (where anomalies peak, see Fig. $12 \mathrm{~b}$ below) reach $0.1 \mathrm{dyn} \mathrm{cm}^{-2} \mathrm{~K}^{-1}$, so that the ratio of anomalies of equatorial wind stress to SST is again of the order of 0.1 dyn $\mathrm{cm}^{-2} \mathrm{~K}^{-1}$. The oscillations in SST, zonal wind stress, and SOI are stronger than their counterparts in decade I, and the correlations between them are more pronounced $(0.89$ and -0.86 , respectively), very suggestive of ENSO-like coupled processes. In contrast to decade $I$, the oscillation in decade II includes a lower-frequency component, which we 
(a) SST Decade I

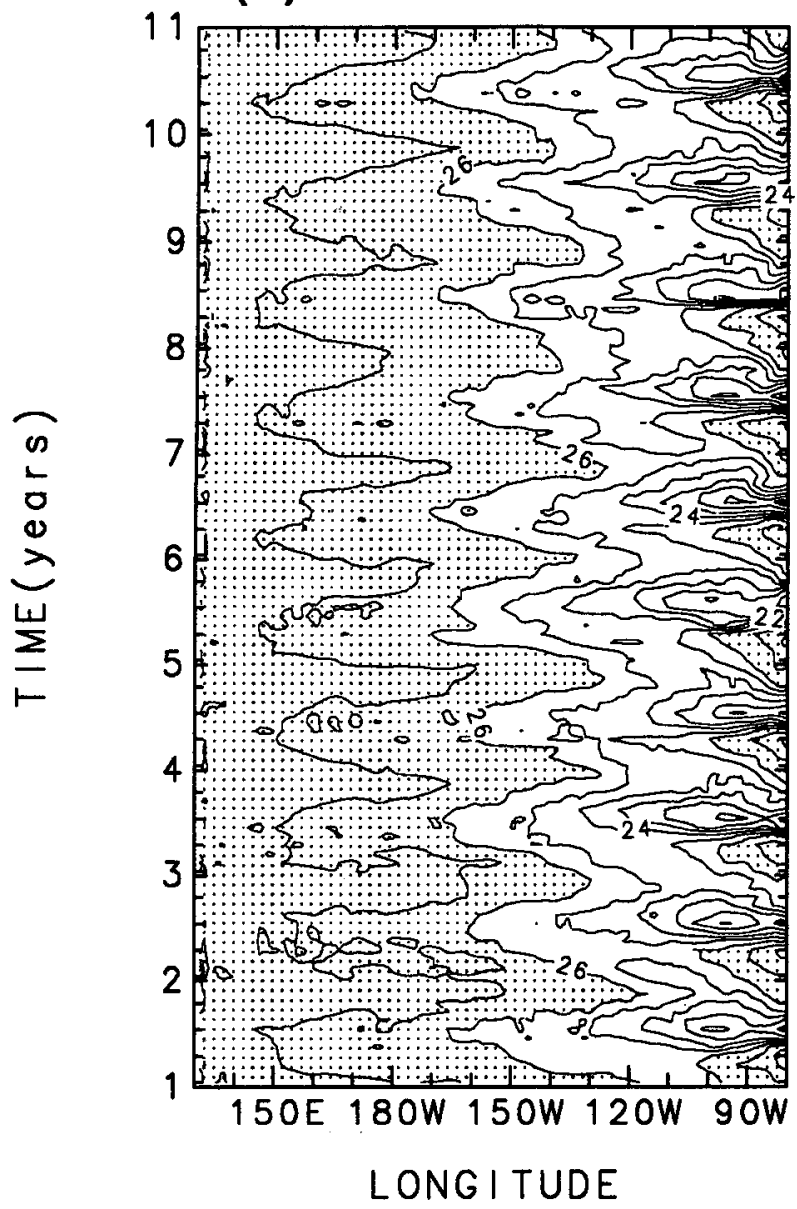

(b) SST Anomaly Decade I

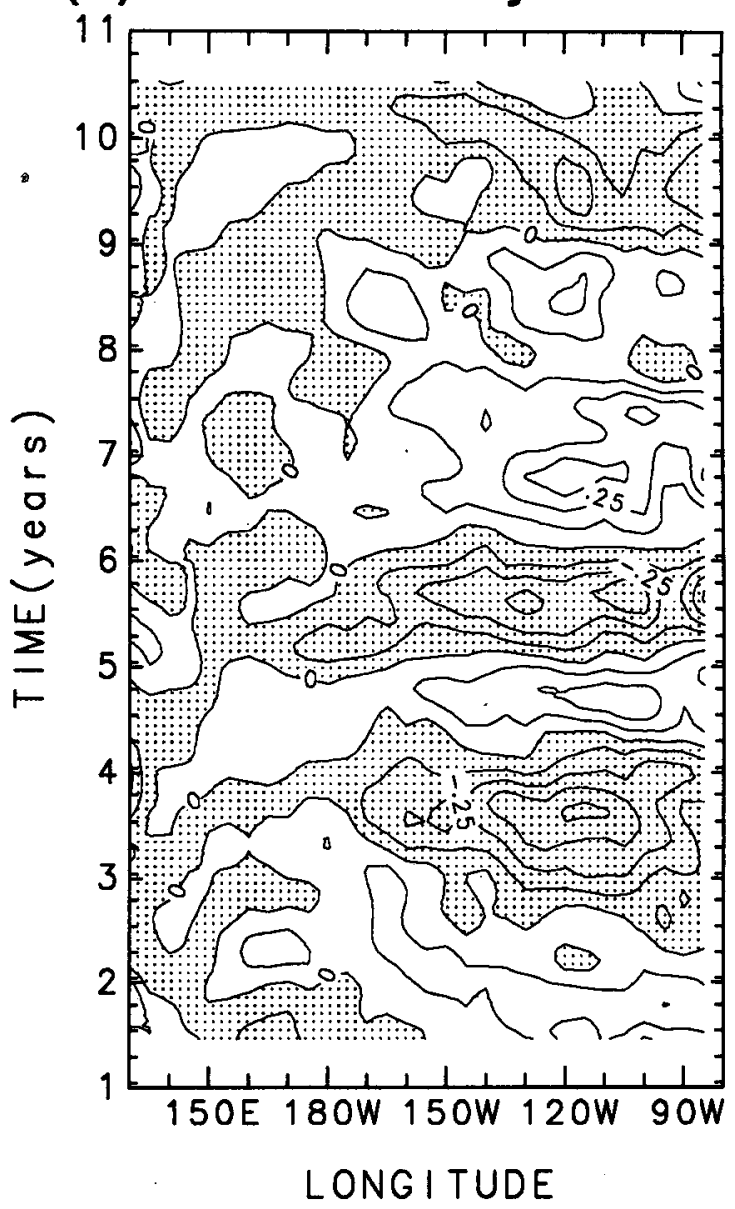

FIG. 2. Hovmoeller diagrams of SST at the equator for decade I. (a) Total field on OGCM grid (contour interval $1 \mathrm{~K}$, stippling $>26^{\circ} \mathrm{C}$ ). (b) Deviation from mean seasonal cycle on AGCM grid $\left(4^{\circ} \mathrm{N}-4^{\circ} \mathrm{S}\right)$, detrended and low-pass filtered at $T \sim 10$ months. Contour interval is $0.125 \mathrm{~K}$; negative values stippled.

isolate in the next section as having a quasi-quadrennial (QQ) period.

\section{Singular spectrum analysis (SSA) results}

A substantial body of work indicates that ENSO involves coupled oscillations of the tropical atmosphereocean system and that these oscillations are essentially linear in character. If this is the case in the CGCM, the curves in Figs. 3 and 5 might be interpreted in terms of a dominant near-periodic component, plus a stochastic component associated with the many degrees of freedom of the CGCM. To isolate any such near periodicities, we apply the M-SSA that was used in Part I to examine the CGCM's seasonal cycle along the equator. Given the model's weak interannual variability and the shortness of the simulations at hand, SSA can still help us extract reliable information from these short, noisy time series, with limited prior knowledge of the underlying physics (cf., Vautard et al.
1992). M-SSA is applied to each simulation in turn to explore spatial and cross correlations that may illuminate the physics underlying the CGCM's interannual variability in the equatorial Pacific. Rasmusson et al. (1990), using single-channel SSA, were able to isolate a QB mode in observed SSTs and surface winds over the equatorial Pacific. Recently, Jiang et al. (1992) have corroborated this QB mode in observed data using MSSA and, in addition, found a QQ mode that sharpens the broadly defined low-frequency variability mentioned by Rasmusson and colleagues.

M-SSA is an empirical orthogonal function (EOF) analysis of lagged data. Details of the methodology are given in Part I together with extensive references, and in Vautard et al. (1992). The orthogonality of the spatiotemporal EOFs in M-SSA is much less problematic than in the ubiquitous spatial EOF technique. Whereas geophysical phenomena are rarely characterized by spatial orthogonality, orthogonality in the time domain is a hallmark of an oscillation. In M-SSA, pairs of nearly 


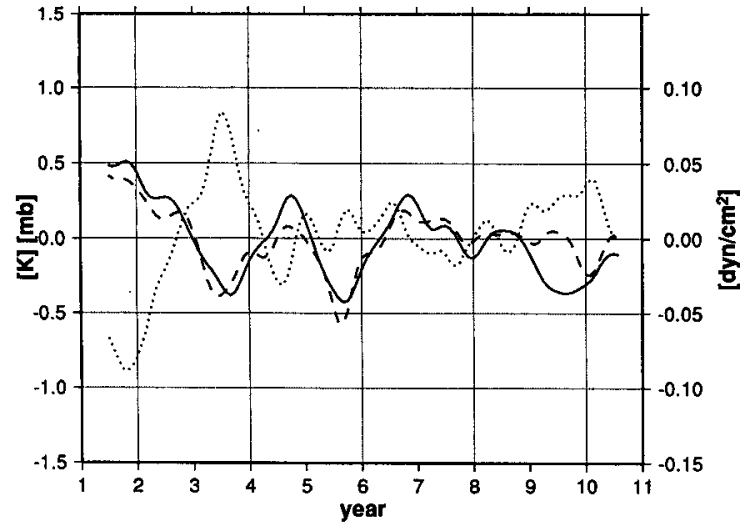

FiG. 3. Anomaly indices for decade I. Solid curve-SST anomaly averaged over the region $130^{\circ}-110^{\circ} \mathrm{W}, 4^{\circ} \mathrm{S}-4^{\circ} \mathrm{N}$; dashed curvezonal wind stress anomaly averaged over the region $170^{\circ}-120^{\circ} \mathrm{W}$, $4^{\circ} \mathrm{S}-4^{\circ} \mathrm{N}$; and dotted curve-difference in sea level pressure between $140^{\circ} \mathrm{E}, 2^{\circ} \mathrm{S}$ and $120^{\circ} \mathrm{W}, 2^{\circ} \mathrm{S}$. All curves have been low-pass filtered at $\sim 10$ months.

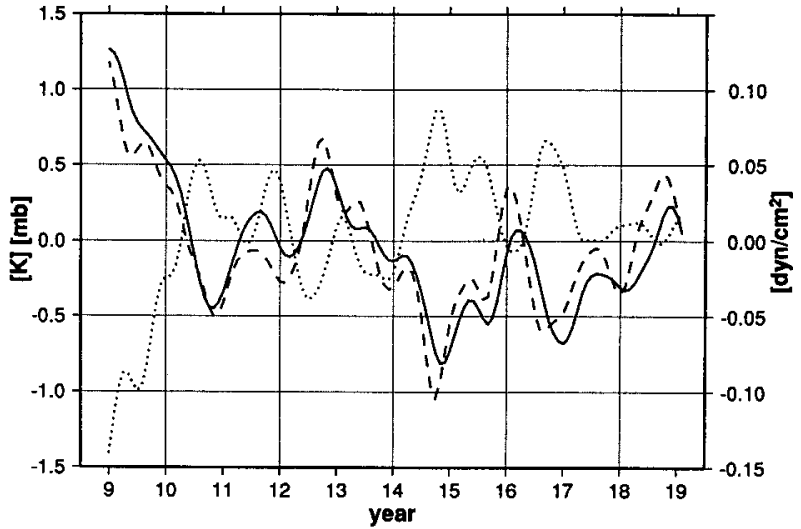

FIG. 5. Anomaly indices for decade II. Same as Fig. 3 except that both SST and zonal wind stress anomalies are averaged over the region $160^{\circ}-140^{\circ} \mathrm{W}, 4^{\circ} \mathrm{S}-4^{\circ} \mathrm{N}$. (a) SST Decade II

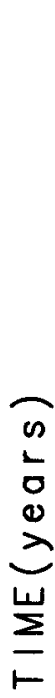

(b) SST Anomaly Decade II

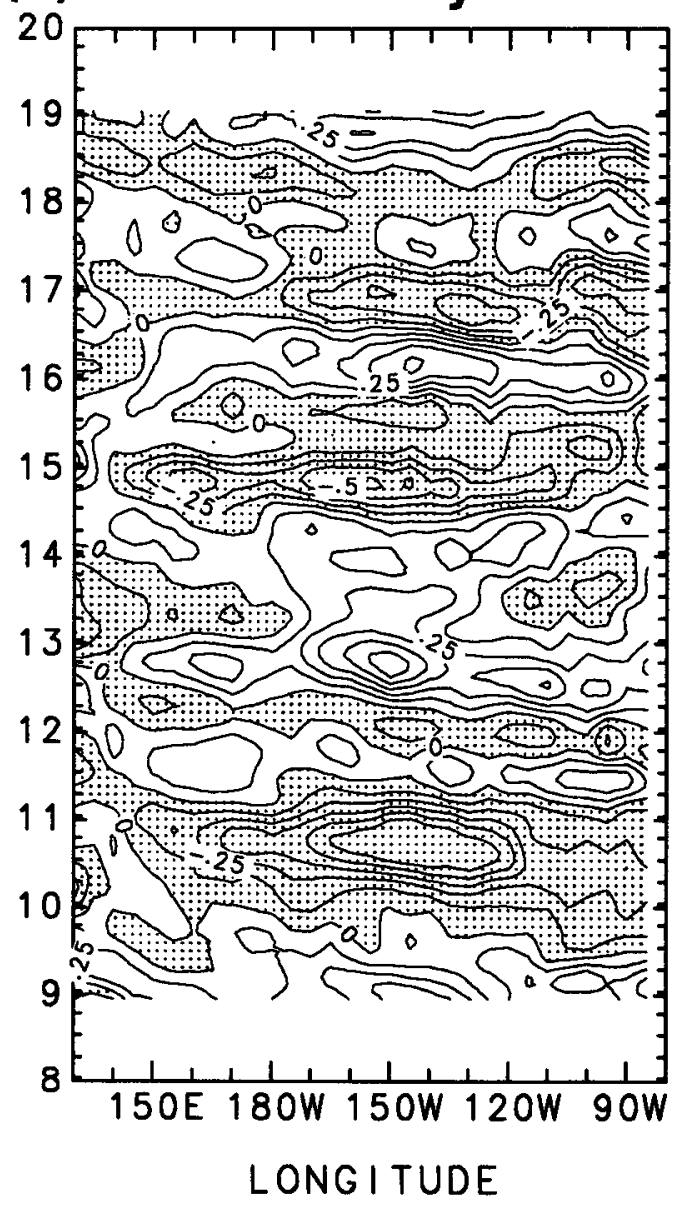

FIG. 4. Equatorial SST for decade II. Same as Fig. 2.

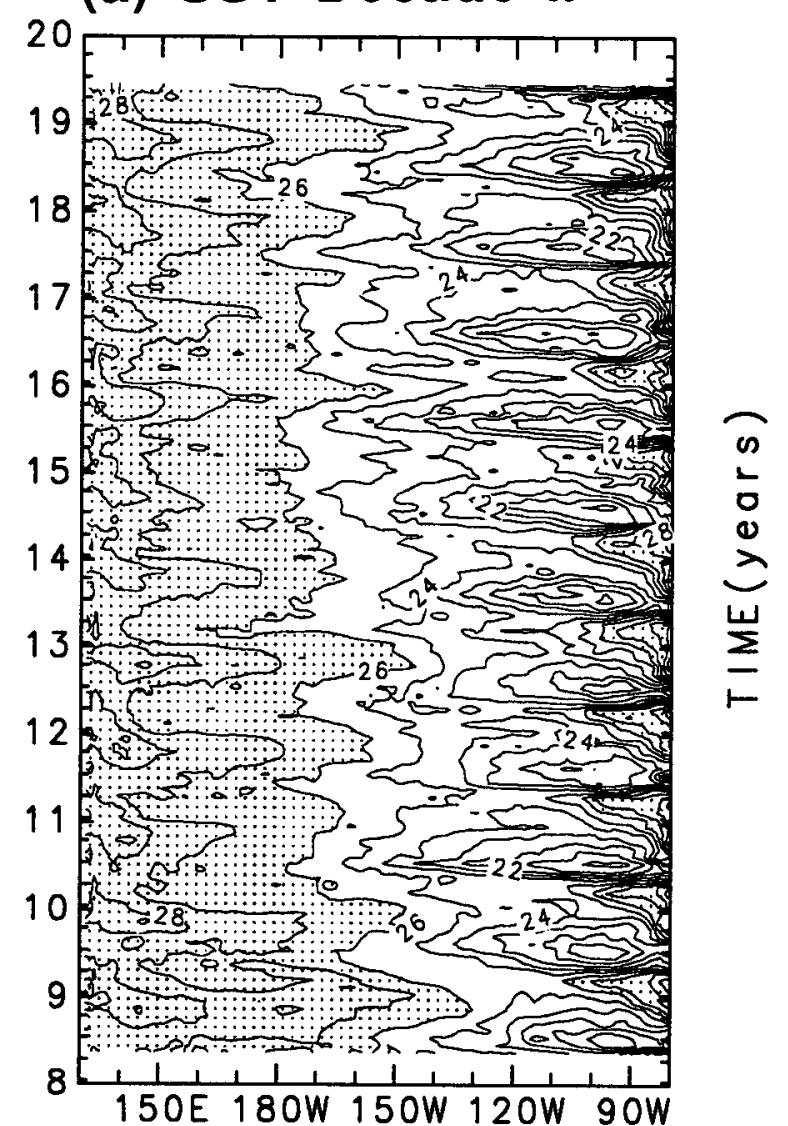

LONGITUDE 
TABLE 1. The leading M-SSA modal pairs of various equatorial anomalies in decade I. The thermocline depth is taken as the depth of the $20^{\circ} \mathrm{C}$ isotherm. The equatorial undercurrent is the zonal current velocity averaged over $100-150-\mathrm{m}$ depth, with the equatorial surface current averaged over $0-30 \mathrm{~m}$. The equatorial upwelling is averaged over 25-95-m depth. A low-pass 11 -point Gaussian filter with a halfpower point near 10 months was applied to the ocean velocities, and the resulting variances are given in brackets. The approximate periods were estimated by inspection of graphs of the power spectra; $\mathrm{O}(M)$ means "of the order of the window length," that is, 60 months.

\begin{tabular}{|c|c|c|c|}
\hline \multicolumn{4}{|c|}{ Decade I } \\
\hline Field & $\begin{array}{l}\text { Modal } \\
\text { pair }\end{array}$ & $\begin{array}{l}\text { Variance } \\
(\%)\end{array}$ & $\begin{array}{c}\text { Approximate } \\
\text { period } \\
\text { (months) }\end{array}$ \\
\hline \multirow[t]{2}{*}{ SST } & $1-2$ & 33.6 & 27 \\
\hline & $3-4$ & 16.2 & $O(M)$ \\
\hline$\tau_{x}$ & $1-2$ & 6.7 & 28 \\
\hline \multirow{2}{*}{$\begin{array}{l}\text { Thermocline depth } \\
\text { (TCD) }\end{array}$} & $1-2$ & 23.4 & 27 \\
\hline & $3-4$ & 8.9 & $\mathrm{O}(M)$ \\
\hline \multirow[t]{2}{*}{$\mathrm{SST}+\tau_{x}+\mathrm{TCD}$} & $1-2$ & 19.8 & 27 \\
\hline & $3-4$ & 9.2 & $\mathrm{O}(M)$ \\
\hline Net heat flux into ocean & $1-2$ & 8.1 & 26 \\
\hline Undercurrent (low pass) & $1-2$ & (35.4) & 26 \\
\hline Surface current (low pass) & $1-2$ & (41.6) & 26 \\
\hline \multirow{2}{*}{ Upwelling (low pass) } & $1-2$ & (31.6) & 40 \\
\hline & $3-4$ & $(23.0)$ & 18 \\
\hline \multirow[t]{3}{*}{ SST with seasonal cycle } & $1-2$ & 60.1 & 12 \\
\hline & $3-4$ & 11.9 & 6 \\
\hline & $5-6$ & 9.4 & 27 \\
\hline
\end{tabular}

equal eigenvalues are generally associated with near periodicities in the time series (Vautard and Ghil 1989), since oscillatory behavior generally involves a complex frequency, that is, two degrees of freedom. The orthogonality constraint in SSA can still give rise to spurious oscillatory modes consisting of pairs of inquadrature eigenmodes. However, if the time series of the two projection coefficients-the principal components (PCs) - of an eigenmode pair contain spells of sinusoidal-type behavior, then a near periodicity is likely to be present (Ghil and Vautard 1991). Such periodic activity suggests in turn the presence of weakly unstable periodic orbits within the system's attractor (Vautard et al. 1992).

\section{a. Decades I and II}

The data were preprocessed by subtracting the mean seasonal cycle for each simulation, and detrending. We also normalize the time series that serve as SSA "channels" by their standard deviations. If the seasonal cycle is not explicitly removed, it tends to contaminate the lower-frequency modes, although Table 1 indicates that the results are not significantly changed. The method is applied first to SST using nine channels consisting of monthly mean box averages of SST along an equatorial strip $\left(4^{\circ} \mathrm{S}-4^{\circ} \mathrm{N}\right)$ every $10^{\circ}$ from $180^{\circ} \mathrm{E}$ to $90^{\circ} \mathrm{W}$, following Jiang et al. (1992). A window length of 5 years (i.e., 61 monthly lags) is chosen to resolve oscil- lations with periods between 1 and 5 years (Vautard et al. 1992). Decades I and II are 120 and 132 months long, respectively, which is rather short with respect to the window length, so that sampling errors may contaminate the largest lags of the autocovariance functions (Vautard et al. 1992).

The leading 20 eigenvalues of the analysis applied to SST for each simulation are plotted in Fig. 6 The spectra contain various breaks and points of inflection, suggestive of about 10 degrees of freedom being dynamically most significant in both decades I and II. However, since the time series is relatively short, we restrict our attention to the leading pair in each case. In decade $\mathbf{I}$, this pair is clearly separated from the rest of the spectrum and accounts for $33.5 \%$ of the variance, while the separation is slightly less pronounced in decade II, with $22.3 \%$ of the variance accounted for. These are both very substantial fractions of the interannual variance, bearing in mind that no prefiltering of the monthly mean SSTs was performed. Strong prefiltering was found to be essential for a Principal Oscillation Pattern (POP) analysis (Storch et al. 1988) of decade

(a) Decade I

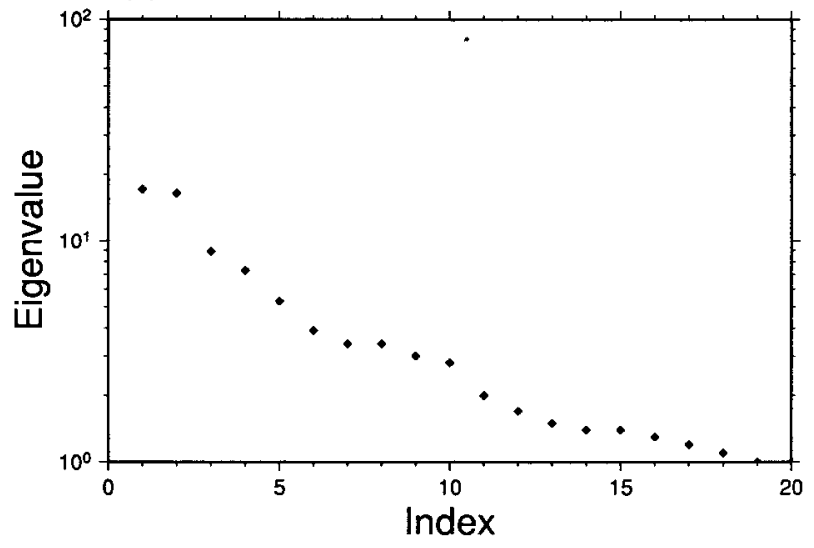

(b) Decade II

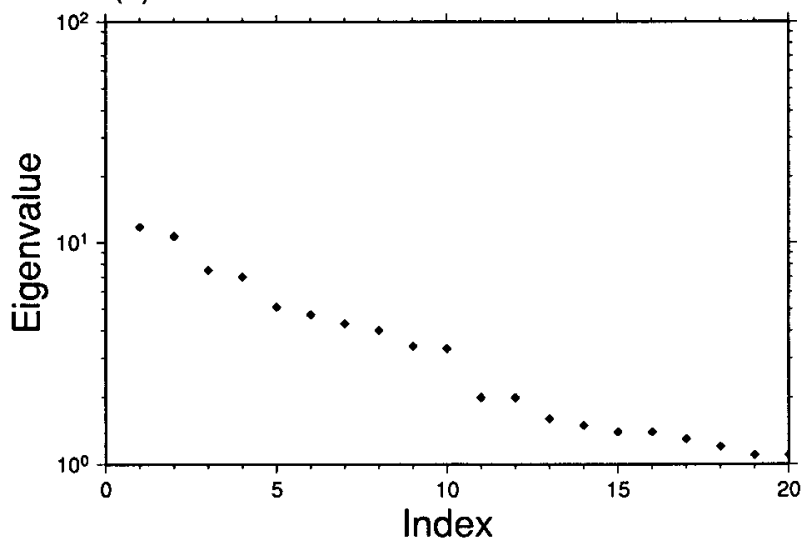

FIG. 6. Leading 20 eigenvalues of M-SSA for SST during (a) decade I and (b) decade II. The eigenvalues are scaled to be percentages of the total variance. 
(a) Decade I

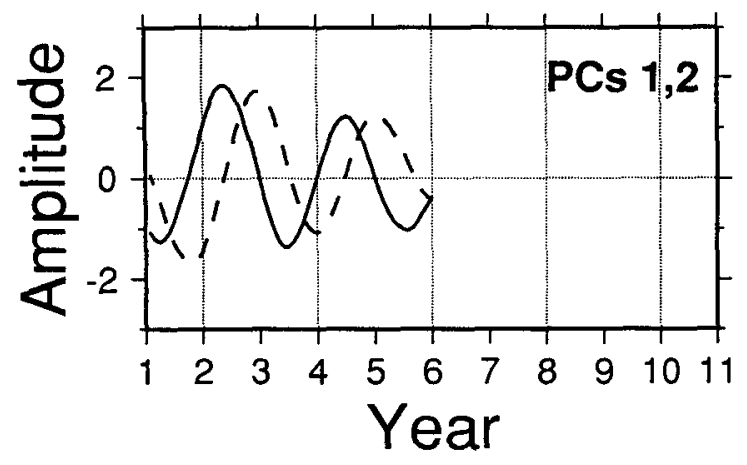

(b) Decade II

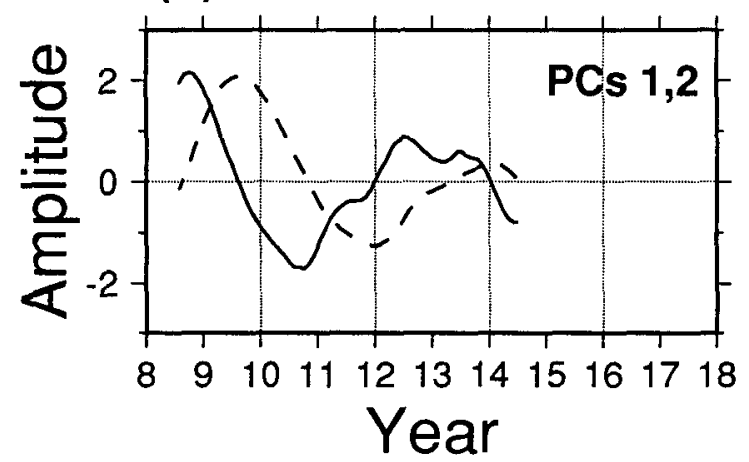

FIG. 7. Normalized PCs 1 (solid) and 2 (dashed) for (a) decade I and (b) decade II.

I (Robertson et al. 1992). The associated PCs are plotted in Fig. 7, and their respective power spectra in Fig. 8. The latter were computed using the maximum entropy method (MEM) (Burg 1967), according to the numerical recipe of Press et al. (1986). Penland et al. (1991) have shown that prefiltering a time series by SSA permits the use of low-order MEM. This combined SSA-MEM method yields the same high spectral resolution as high-order MEM without SSA but avoids the spurious peaks for which the latter is notorious.

The leading two PCs of decade I (Fig. 7a) are close to sinusoidal, are in quadrature with each other, and have a common decay time. Correspondingly, they both have power spectra (Fig. 8a) that peak sharplyat about 27 months-consistent with the QB signal noted in Figs. 2 and 3. The near periodicity in this mode is remarkable and strongly suggests a nearly periodic orbit.

The PCs of the leading pair for decade II (Fig. 7b) are also fairly sinusoidal and in quadrature, although PC 1 has a slightly richer harmonic content (cf. also Fig. $8 \mathrm{~b}$ ), consistent with less precise pairing in their eigenvalues. Still, the associated power spectra both peak sharply at about 48 months (Fig. 8b), indicating a near periodicity that is a subharmonic of the annual cycle. Eigenmodes 3 and 4 of decade II also form a pair, as suggested by Fig. 6b and corroborated by inspection of their PCs and power spectra (not shown). This oscillation has a period of about 18 months and is less regular than those associated with the leading pairs. Both leading modes in decade II have been corroborated by integrating the model for a further 26 years; see section $4 b$.

In both simulations, the leading near periodicities are approximate subharmonics of the annual cycle. Furthermore, though perhaps fortuitously, these are also the periods that Jiang et al. (1992) found to dominate the Comprehensive Oceanic and Atmospheric Data Set (COADS) fields of SST and surface zonal wind. In our CGCM, however, the two modes appear to mutually exclude one another in the two simulations.

The spatial structure associated with each modal pair may be expressed in terms of the component of the

(a) Decade I

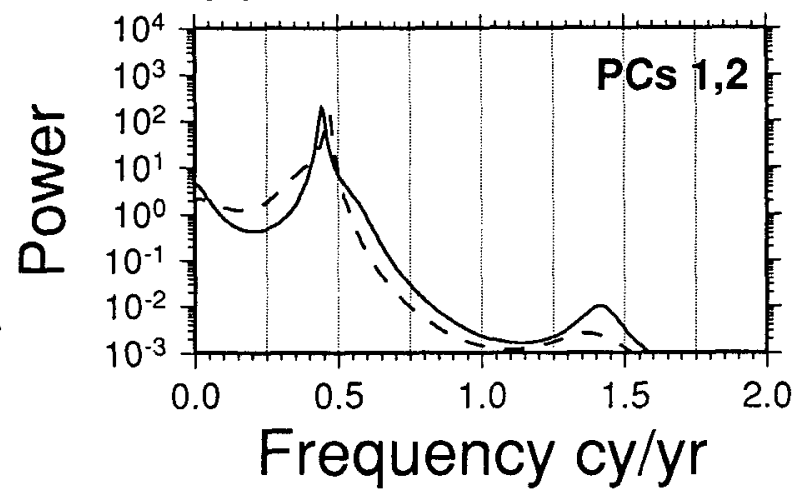

(b) Decade II

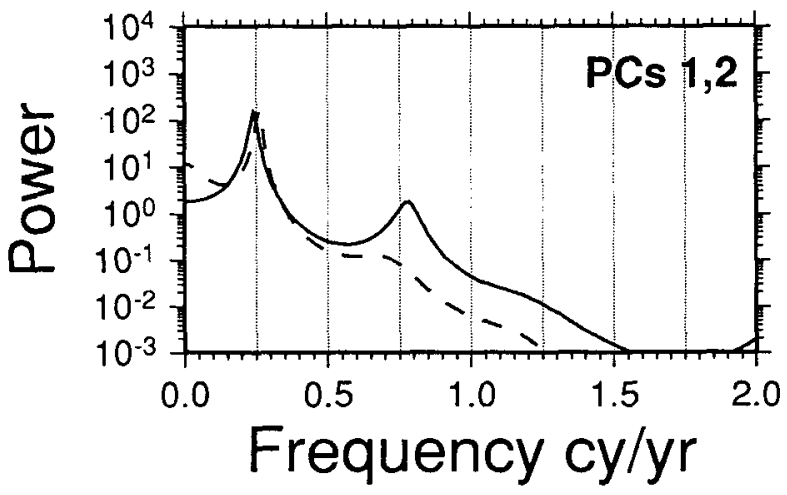

FIG. 8. Power spectra of PCs 1 (solid) and 2 (dashed) for (a) decade $I$ and (b) decade II. The maximum entropy method (MEM) was used with 20 poles and 300 frequency intervals. 
original time series that can be reconstructed from it, that is, the reconstructed components (RCs), as in part I. Summing all the RCs of all 549 ( 9 channels $\times 61$ lags) eigenmodes should recover the original data (Vautard et al. 1992), and this was verified to be the case. The RCs for each leading pair are shown in Fig. 9. These two modal pairs capture the essence of the differing interannual variabilities in the two simulations, which are visible in the Hovmoeller diagrams of Figs. 2 and 4, respectively. In decade I, the dominant QB component in equatorial SST consists of a predominantly stationary oscillation with a maximum near $120^{\circ} \mathrm{W}$. The mode's stationarity and maximum location correspond well to the observed QB mode found by Jiang et al. (1992), although the latter extends to the date line. The QQ mode in decade II peaks near $150^{\circ} \mathrm{W}$, but it too is predominantly stationary, with a weak tendency to propagate westward. The QQ mode isolated by Jiang et al. (1992) in COADS data is also stationary in phase, but it peaks farther east at $120^{\circ} \mathrm{W}$. The second mode of an interannual canonical correlation analysis using observed SST and wind stress anomalies (Gutzler 1992, personal communication) also peaks in the central Pacific.

Both simulated modes in Fig. 9 are evanescent. This is even more obvious in Fig. 10, which shows time series of reconstructed SST averaged over the same regions used to construct the respective anomaly indices in Figs. 3 and 5. The RCs of the leading three modal pairs are shown for each simulation. The large initial amplitude of the leading pair in each case appears to be triggered by dynamic imbalance: the ocean at rest in decade I, and the modification to the fluxes at the ocean-atmosphere interface in decade II. During years 4-7 of decade $I$, the QB oscillation is almost in phase with the seasonal cold tongue, and it is during this interval that it is visible in the Hovmoeller diagram of anomalous SST (Fig. 2b). However, it is not phase locked to the annual cycle in the way that the QQ mode of decade II appears to be. The QQ mode has larger amplitude than the QB, in agreement with the observed field evolution (Jiang et al. 1992), although both simulated modes are weaker than their observed counterparts by about a factor of 2 . Figure 10 also shows a (a) RCs Decade I

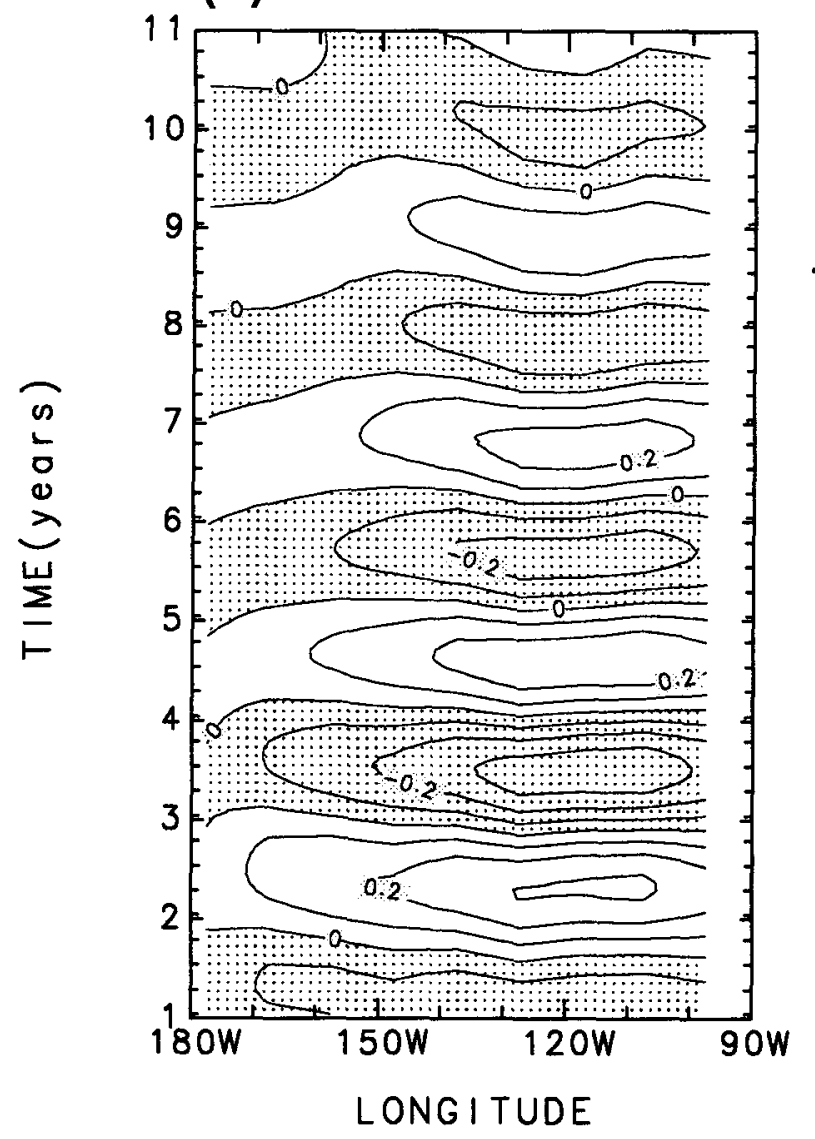

(b) RCs Decade II

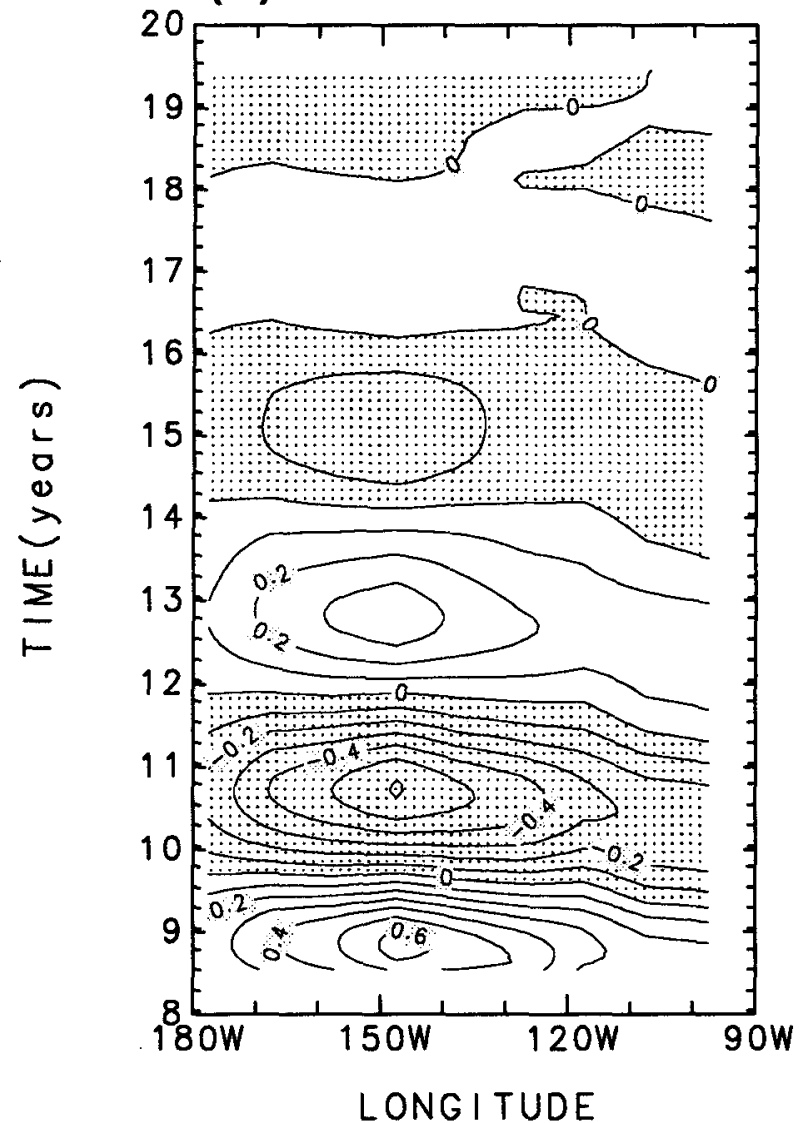

FiG. 9. Hovmoeller diagrams of RCs $1-2$ of SST for (a) decade I and (b) decade II. Contour interval is $0.1 \mathrm{~K}$, and negative anomalies are stippled. 
(a)

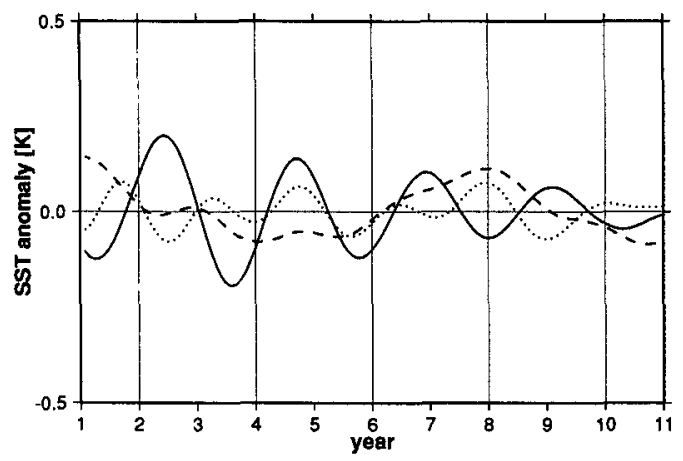

(b)

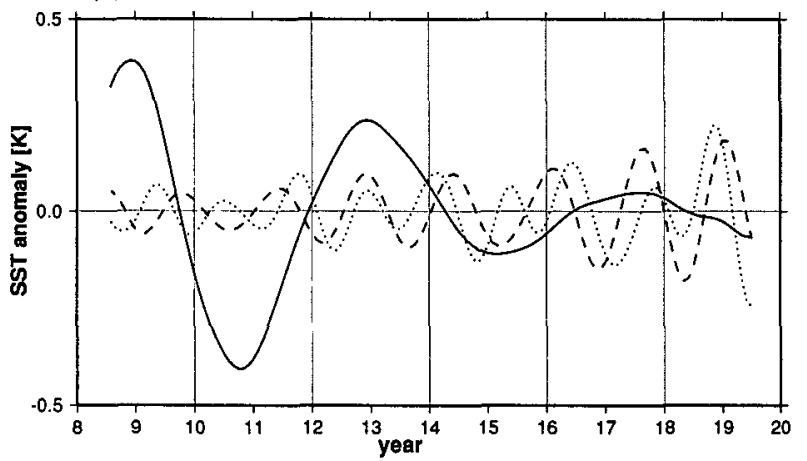

FIG. 10. Anomaly indices constructed from RCs of SST for (a) decade I $\left(130^{\circ}-110^{\circ} \mathrm{W}, 4^{\circ} \mathrm{S}-4^{\circ} \mathrm{N}\right)$ and (b) decade II $\left(160^{\circ}-140^{\circ} \mathrm{W}\right.$, $4^{\circ} \mathrm{S}-4^{\circ} \mathrm{N}$ ). Key: solid line-RCs 1-2; dashed line-RCs 3-4; and dotted line-RCs 5-6.

lower-frequency 5-6-year mode in decade I (RCs 5$6)$ and an 18-month mode in decade II.

Some idea of the robustness of the results can be obtained by applying a variation of the technique. In the SSA used in this paper, we consider the right-singular modes of the trajectory matrix (see part I), following the "method of delays" of Broomhead and King (1986). This constitutes a very efficient algorithm for the short multichannel time series at hand. However, the associated covariance matrix only approximates a (block) Toeplitz structure. Vautard and Ghil (1989) use a variation of the technique that maintains the Toeplitz structure of the autocovariance matrix explicitly by computing its entries directly using a standard least-biased estimator rather than windowing the data. The latter autocovariance matrix has the advantage of being the discrete analog of the autocovariance function whose eigenfunctions are the modes of interest (see also Allen et al. 1992a,b). Both approaches are equivalent to within sampling error. The leading RC pairs are found to be robust, although the leading eigenvalues are quite sensitive to which method is used. The "method of delays" produced harmonically purer oscillations in the cases studied here.

The results of repeating the analysis with other equatorial variables are tabulated in Tables 1 and 2 for each decade, respectively. Box averages of the respective quantities were constructed similarly to those of SST, except that the longitudinal domain was taken across the whole basin from $140^{\circ} \mathrm{E}$ to $90^{\circ} \mathrm{W}$, and equatorial values were used only for the oceanic quantities. The leading modal pairs were identified by inspection of their constituent PCs and their respective power spectra. Similar dominant modes of interannual variability were found in most cases, although the ocean currents had to be low-pass filtered, and even then no near periodicities could be identified in the surface current and in the upwelling at the equator in decade II. An M-SSA of equatorial sea level pressure failed to isolate a dominant oscillatory mode in either stage of the simulation.

Since both the equatorial atmosphere and ocean exhibit oscillations of similar period, it is likely that the underlying physics involves coupling between the atmosphere and ocean. To investigate this further, MSSA was applied simultaneously to three crucial equatorial fields whose combined signatures largely characterize the state of the coupled atmosphere-ocean system: SST, zonal wind stress $\tau_{x}$, and thermocline depth. The nine-channel state vector used in the SST analysis was simply augmented to 35 channels using the same box averages of $\tau_{x}$ but from $140^{\circ} \mathrm{E}$ to $90^{\circ} \mathrm{W}$ and equatorial $10^{\circ}$ longitude averages of the anomalous depth of the $20^{\circ} \mathrm{C}$ isotherm also from $140^{\circ} \mathrm{E}$ to $90^{\circ} \mathrm{W}$; again, each channel was normalized by its standard deviation. Modes that resemble the univariate analyses were obtained, as summarized in Tables 1 and 2. This similarity attests to the coherence of the oscillation in each case.

To show the multivariate phase relations, we plot the RCs of the leading single-field pairs of anomalous SST, zonal wind stress, and thermocline depth in Figs. 11 and 12 for decades I and II, respectively. Only a 5-

TABLE 2. Same as Table $\mid$ but for Decade II.

\begin{tabular}{lccc}
\hline \hline & Decade II & \\
\hline \multicolumn{1}{c}{ Field } & Modal & Variance & $\begin{array}{c}\text { Approximate } \\
\text { period } \\
\text { (months) }\end{array}$ \\
\hline SST & $1-2$ & 22.3 & 48 \\
& $3-4$ & 14.5 & 18 \\
$\tau_{x}$ & $1-2$ & $(30.0)$ & 43 \\
Thermocline depth & $1-2$ & 15.8 & 48 \\
(TCD) & $3-4$ & 12.7 & 15 \\
SST $+\tau_{x}+$ TCD & $1-2$ & 13.4 & 48 \\
Net heat flux into ocean & $3-4$ & 9.7 & 15 \\
Undercurrent (low pass) & $1-2$ & 6.5 & 48 \\
Surface current & $1-2$ & $(24.6)$ & 48 \\
Upwelling & - & - & - \\
SST with seasonal cycle & $1-2$ & -28.4 & -12 \\
& $3-4$ & 11.8 & 48 \\
& $5-6$ & 9.1 & 6 \\
\hline
\end{tabular}


year interval (the window length) is shown in each case for clarity. Each RC was derived by applying MSSA to each field separately, although very similar figures result from the combined multifield analysis. There is a clear wind-stress signature associated with the QB mode, consisting of anomalies of the same sign as those of the SST, that peak to the west of the latter. This picture is repeated in the case of the QQ mode (decade II), although the spatial phase shift is reduced. The ratio of wind stress to SST anomalies is of the order of 0.1 dyn $\mathrm{cm}^{-2} \mathrm{~K}^{-1}$ in both cases, with the $\mathrm{QB}$ ratio slightly greater, which is consistent with Figs. 3 and 5. Temporally, the QB stress anomaly appears to lead SST slightly and propagates westward, while the QQ stress signature is almost in phase with SST. To the east of the SST anomaly maxima, the stress anomaly changes sign - especially in decade II - in agreement with simple linear atmospheric models (Gill 1980). However, the main stress anomaly is not phase shifted west of the SST anomaly as much as observed in either mode. Such a westward shift is thought to be a result of the nonlinear effect of total SST on gross moist stability, since the latter largely determines the location of the low-level convergence (Neelin and Held 1987). The weak mean gradient of SST along the equator in the central Pacific in the CGCM (see part I) is a plausible explanation for the underestimated westward phase shift between anomalies of SST and stress. An uncoupled integration of the AGCM-with observed SSTs prescribed-does not exhibit this deficiency.

Thermocline depth anomalies in Figs. $11 \mathrm{c}$ and $12 \mathrm{c}$ peak near the eastern edge of the basin ahead of SST and decrease in amplitude westward. Nevertheless, there is a phase shift of about $90^{\circ}$ across the basin, with anomalies in the west leading those in the east. Qualitative Sverdrup balance is visible in the region of the wind-stress anomaly maxima; this is. less clear farther west, where the thermocline deepens, so that the $20^{\circ} \mathrm{C}$ isotherm may not reflect the vertically integrated pressure gradient. Maximum thermocline displacements are about $10 \mathrm{~m} \mathrm{~K}^{-1}$ of SST anomaly and lead SST and wind stress by several months in both simulations. This interannual thermocline signature is similar to that of the annual cycle in Part I and the linear response to periodic, zonally uniform forcing found by Cane and Sarachik ( 1981 ) in a shallow-water model.

In contrast to our model, other CGCMs (Philander et al. 1992; Nagai et al. 1992) and uncoupled OGCMs forced with observed wind stresses (Chao and Philander 1993) exhibit large thermocline-depth anomalies in the equatorial west Pacific. These anomalies generally peak off the equator and are associated with anomalies in wind-stress curl (Philander et al. 1992). An M-SSA of thermocline depth at $2.5^{\circ} \mathrm{N}$ did detect the $\mathrm{QB}$ and $\mathrm{QQ}$ modes as the leading modes in the respective simulation decades, using low-pass filtering (though they could not be isolated at $6^{\circ} \mathrm{N}$ ). However, neither mode exhibits large amplitudes west of the date line, and this is consistent with the eastward location of the windstress anomaly maxima in the two present simulations.

Figure 13 shows the corresponding RCs for the anomalous equatorial currents in decade $I$. In the eastern part of the basin, the surface and undercurrents are approximately in quadrature with each other, as is the case for the annual cycle in Part I; they become almost in phase west of the date line. Both exhibit westward propagation. To a first approximation, the surface-current anomalies do resemble a smoothed-out picture of the zonal wind stress, although there is a tendency for the surface current to lead the stress at many longitudes. According to the simple model of Cane (1979), linear theory predicts that the surface shear current will rapidly adjust to the wind on a frictional timescale of about 20 days. However, the nonlinear effects of undercurrent-velocity upwelling become significant on the timescale of the undercurrent. This involves basin-scale adjustment on a timescale of four times the basin-crossing time of the equatorial Kelvin wave, a total of about 8 months (Cane 1979). Thus, the surface current is not a pure local response to the wind, and this is brought out in the respective RCs.

The undercurrent (Fig. 13b) generally lags the zonal wind stress and is weak during the warm SST phase, as observed. Cane's (1979) simple model suggests that apart from the zonal pressure force associated with the tilt of the thermocline, the undercurrent receives a significant contribution from the $\beta$ effect associated with inflow toward the equator at depth. This inflow balances Ekman drift and takes place on the frictional timescale. A further important contribution to the undercurrent is the inertial term (Philander and Chao 1992), since fluid particles tend to stay in the core of the undercurrent, which is a region of horizontal convergence. Figures $11 \mathrm{c}$ and 13 show that in decade I the ocean currents are not in instantaneous equilibrium with the zonal wind stress in a steady-state sense. In decade II, no leading QQ mode was found in the surface current. However, the undercurrent did reveal a QQ signature, with a structure (not shown) almost in antiphase with the zonal wind stress. This behavior contrasts with the larger phase lag in the QB case, but it is consistent with the expectation that, at very low frequency, the ocean reaches equilibrium with the wind stress.

The leading RC pair of the net heat flux into the ocean is shown in Fig. 14. In each case, the net surface heat flux anomalies-which are dominated by the latent component-are in antiphase with the SST anomalies and thus tend to damp both the QB and QQ modes. The heat-flux modes both exhibit a dip in amplitude at the longitude of maximum SST anomaly. This is consistent with the attendant wind-stress anomalies in Figs. $11 \mathrm{~b}$ and $12 \mathrm{~b}$ via their effect on evaporation. 


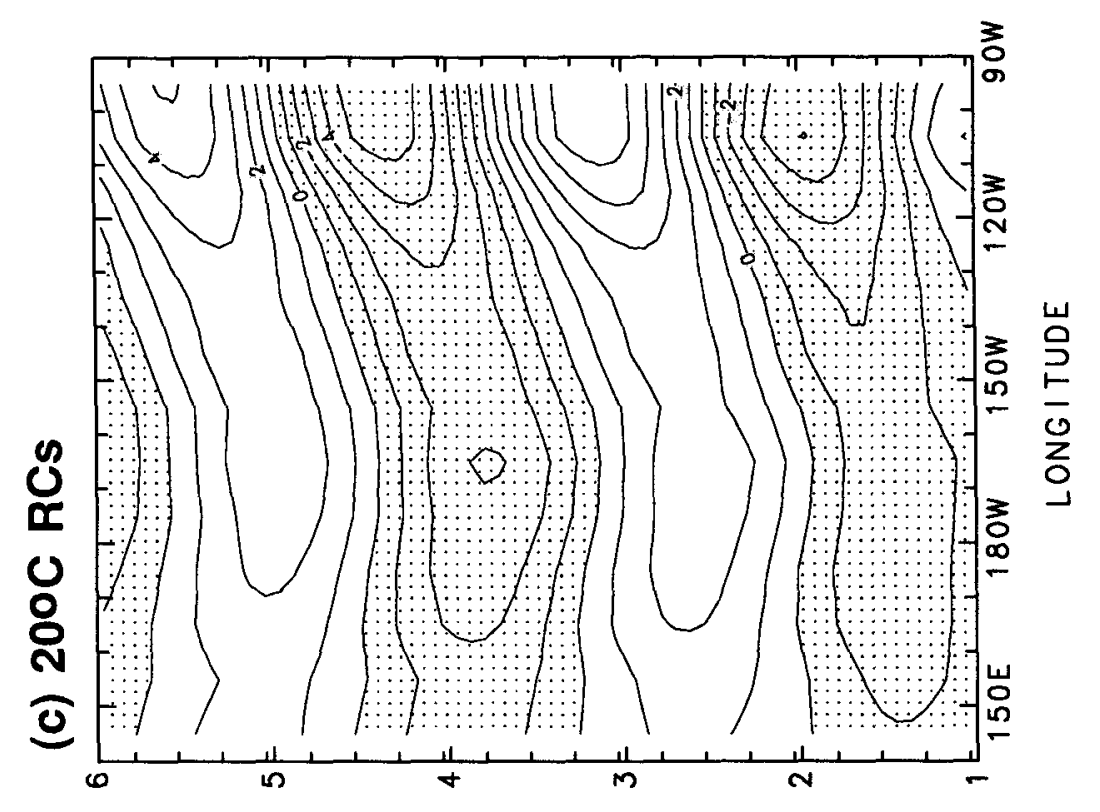

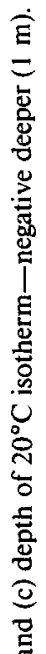

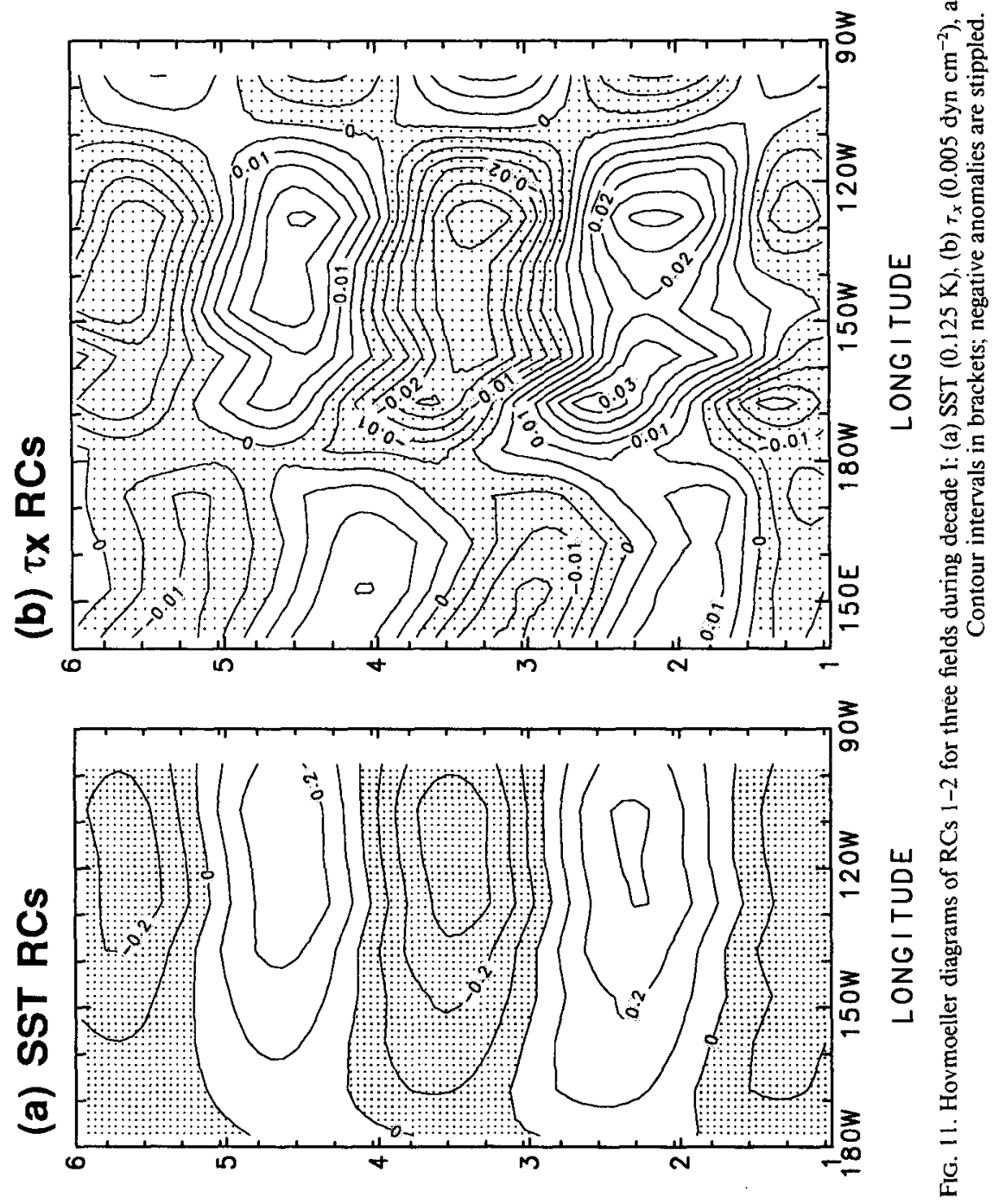

$(S \perp D \partial K) \exists W I \perp$ 

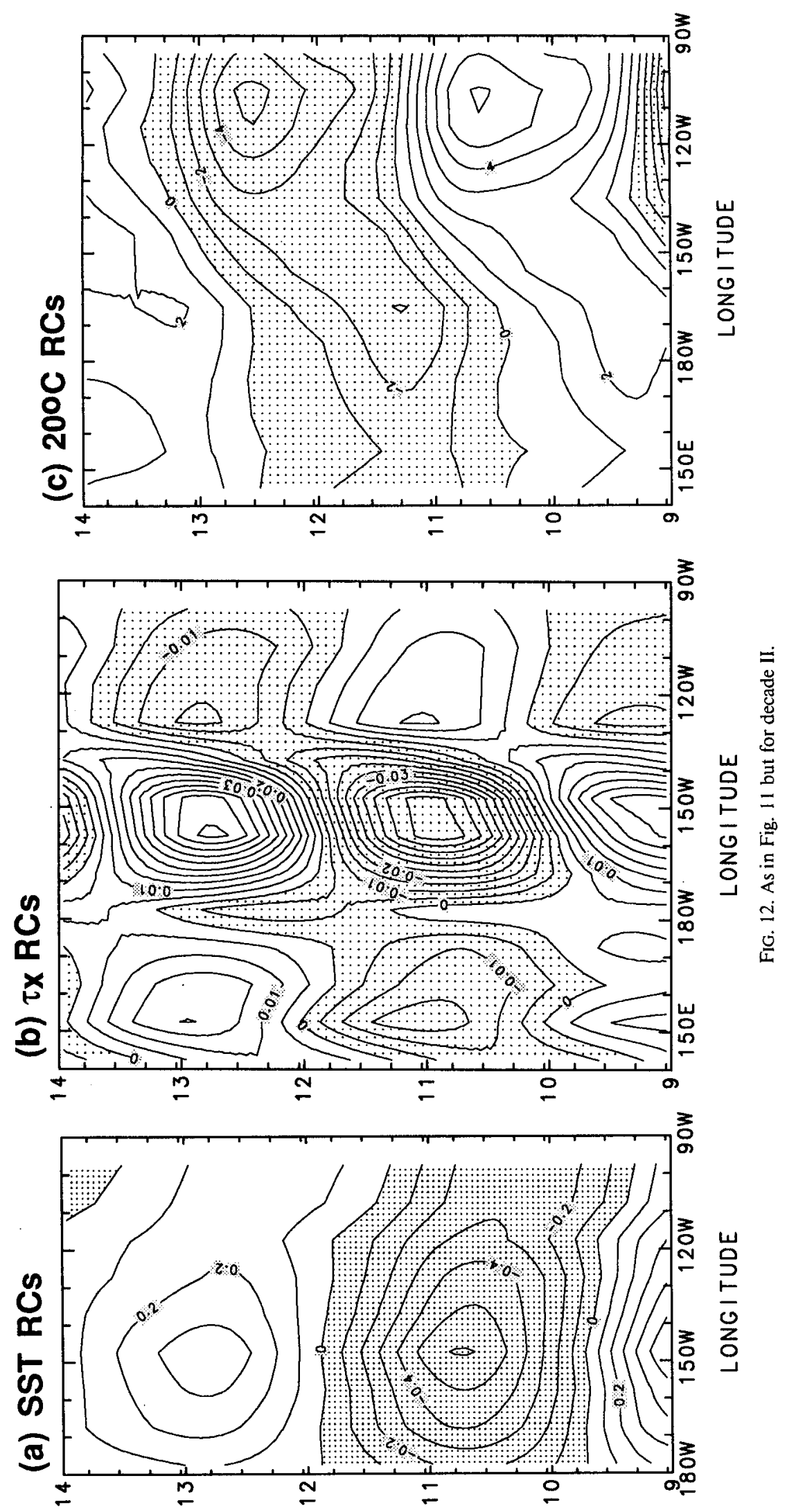

$(s \perp 0 \partial K) \exists W I \perp$ 
To examine the off-equatorial structure associated with the modes, regression maps were constructed between the leading RCs of equatorial SST in Fig. 10 and the simulated monthly mean fields of anomalous SST and wind stress between $30^{\circ} \mathrm{S}$ and $50^{\circ} \mathrm{N}$ (i.e., the OGCM domain). The results are plotted in Fig. 15, where magnitudes have been normalized so that the maximum SST anomaly is $1 \mathrm{~K}$ in each case. Each map represents the spatial structure associated with the peak phase of the oscillation.

The longitudinal structure of anomalous SST and zonal wind stress at the equator recapitulates Figs. 11 and 12. However, in both simulations, the dominant mode of interannual variability in SST is confined to a very narrow equatorial band-much narrower than the observed anomalies characteristic of ENSO. This reflects the narrowness of the model's seasonal cold tongue (Part I). The accompanying wind-stress patterns are correspondingly narrow and lack the spatial coherence seen in observed data. The narrowness of the wind-stress signature is significant since the linear results of Cane and Sarachik (1981) show a large sensitivity to the meridional scale of the forcing. Nevertheless, the convergent wind-stress signatures-associated with positive equatorial anomalies of SST in the CGCM-have a realistically pronounced meridional component. The central Pacific between $20^{\circ}$ and $30^{\circ} \mathrm{N}$ appears to exhibit some correlation with the equatorial QB and QQ oscillations.

\section{b. An additional 26-year simulation}

Decade II is too short for the QQ mode to be convincing. Subsequent to the foregoing analyses, a $26-y \mathrm{r}$ continuation to decade II was simulated to evaluate the mode further. The independent 26-yr run is sufficiently long compared with the QQ period, so that we should be able to confirm or discount this QQ mode. Furthermore, since the mode is evanescent in decade II, it is of great interest to know if the model can sustain any oscillations. The mean state and seasonal cycle in the 26-year extension are very similar to that of decade II (analyzed in part I), and there is very little climate drift.

In addition to repeating the M-SSA of equatorial variables, we further test the statistical significance of the eigenvalues against red noise using a Monte Carlo technique. Rather than taking geographical points along the equator as channels, as in the previous section, we use here the (unnormalized) PCs (S-PCs) of a spatial EOF (S-EOF) analysis of those grid points. Truncating the S-PC expansion allows a compression of covariance into a few channels-crucial when the number of grid points becomes large ( $\mathrm{cf}$. Ghil and Mo $1991 \mathrm{a}, \mathrm{b})$. This preprocessing scarcely affected the results of the M-SSA in the previous section but it facilitates construction of red-noise surrogate data. This is because the S-PCs are uncorrelated at lag zero, whereas the grid points along the equator are highly correlated. (a) Surface current RCs

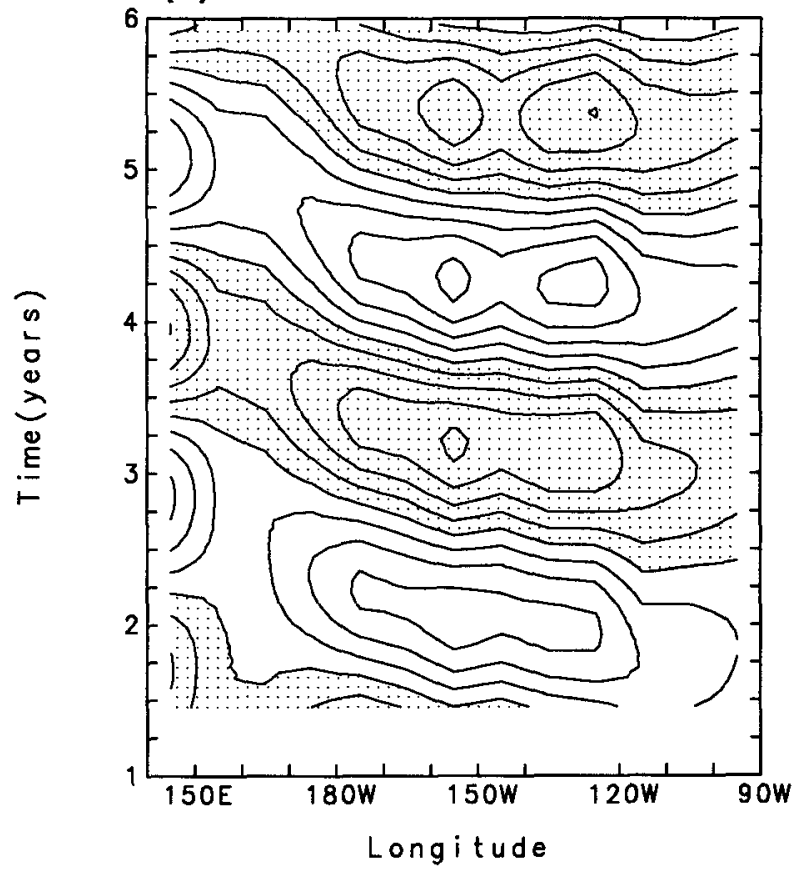

(b) Undercurrent RCs

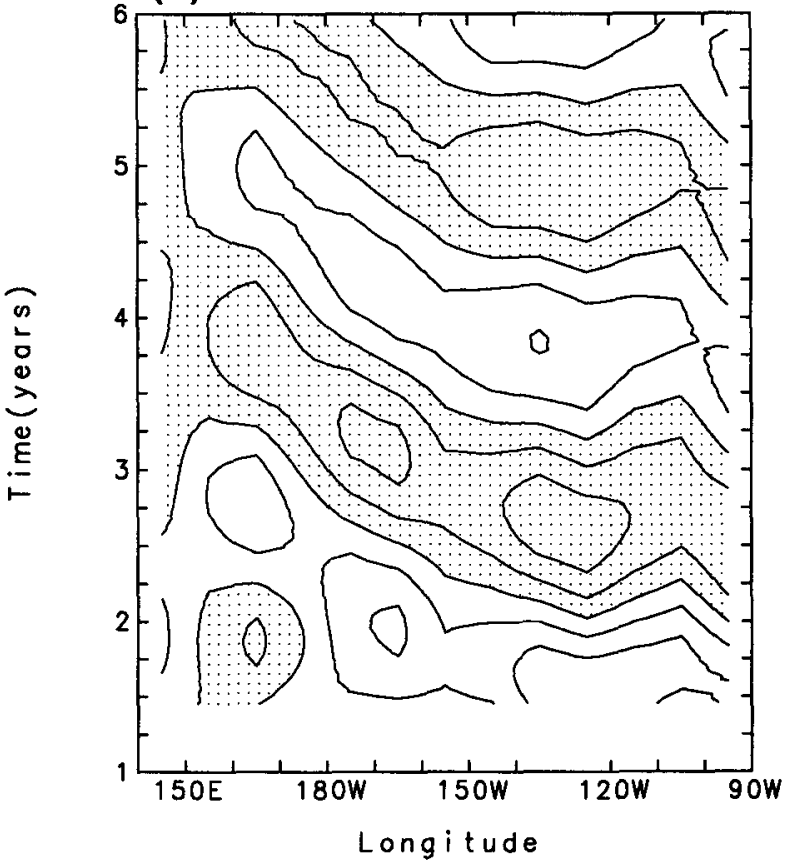

FIG. 13. As in Fig. 11 but for depth-averaged equatorial current anomalies in decade I: (a) surface current $(0-30 \mathrm{~m})$ and (b) undercurrent (100-150 m). Contour interval is $1 \mathrm{~cm} \mathrm{~s}^{-1}$; negative anomalies are stippled.

The M-SSA here is a combined analysis, based upon $5^{\circ}$ gridpoint values of SST and $\tau_{x}$, averaged $4^{\circ} \mathrm{N}-4^{\circ} \mathrm{S}$ from the AGCM grid, together with $5^{\circ}$ longitude av- 
(a) Flux RCs Decade I

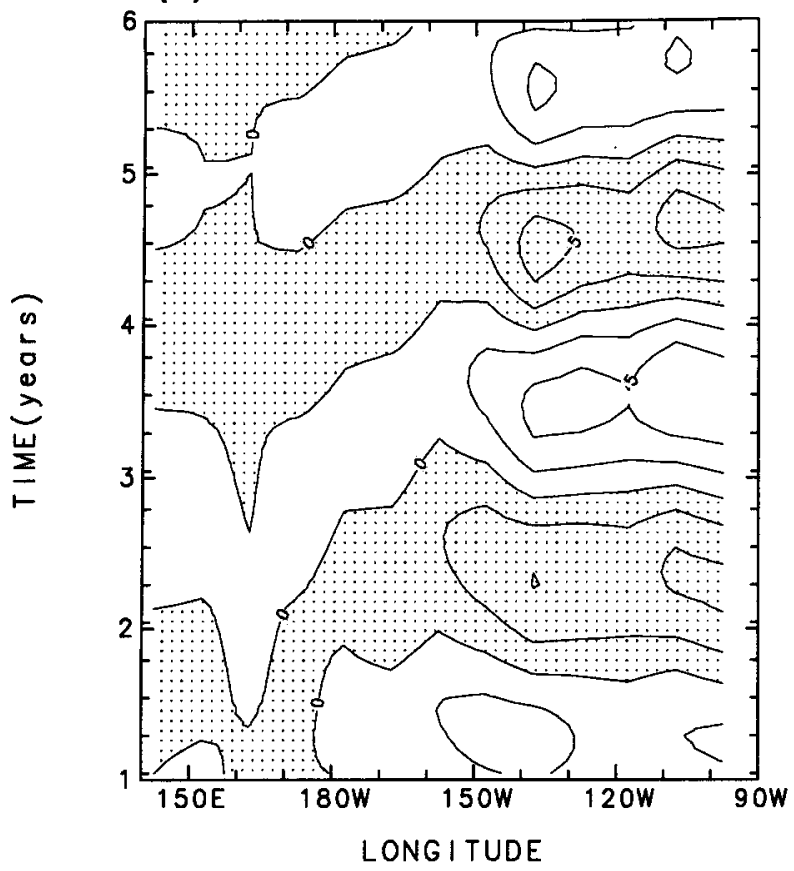

(b) Flux RCs Decade II

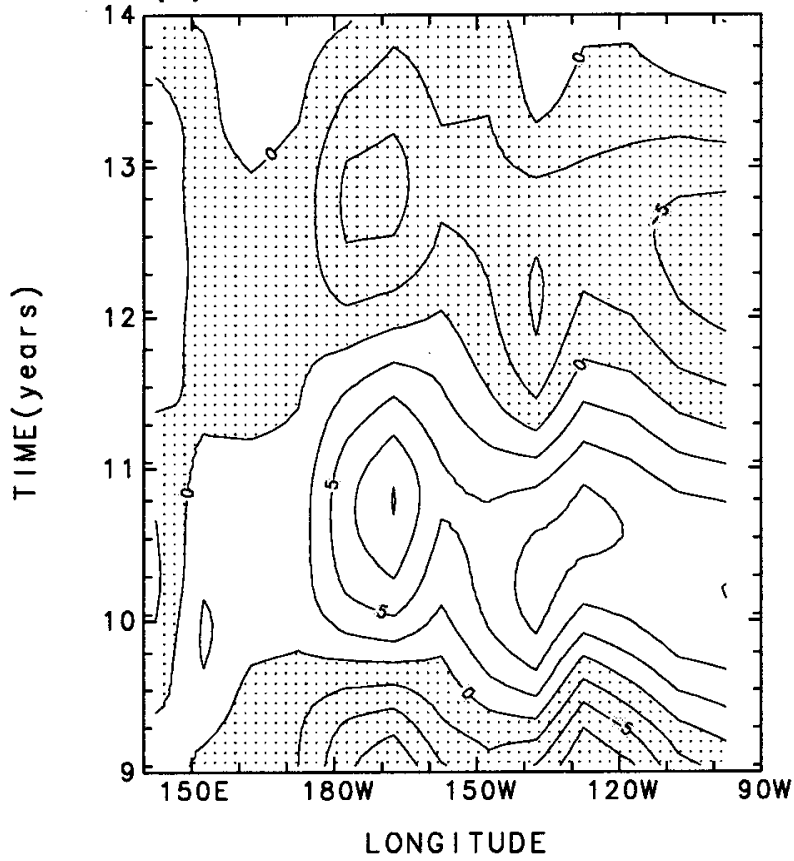

FIG. 14. As in Fig. 11 but for anomalies of the net heat flux into the ocean for (a) decade I and (b) decade II. Contour interval is 2.5 $\mathrm{W} \mathrm{m}^{-2}$; negative anomalies are stippled.

erages along the equator of the depth of the $20^{\circ} \mathrm{C}$ isotherm. The analysis domain is $140^{\circ} \mathrm{E}-80^{\circ} \mathrm{W}$, with 29 values per variable over 312 monthly means. The model-field time series were first detrended and nor- malized by their standard deviation, and the first 10 S-PCs of an S-EOF analysis retained (70\% of the variance). Retaining 20 S-PCs ( $85 \%$ of the variance) produced negligible changes in results.

Figure 16 shows the eigenvalue spectrum, plotted as diamonds, with the 5- and 95-percentage points of the red-noise sample denoted by circles. The noise spectrum was computed from 100 realizations of M-SSA applied to 10 random S-PCs, with the latter drawn from $N\left(0, \lambda_{k}\right)$, where $\lambda_{k}$ is the eigenvalue of the $k$ th sample S-PC. To account for the red-noise character of the model output, the length of the random realizations was reduced to $n_{\mathrm{eff}}=n / T_{e}$, where $n$ is the sample size (i.e., 312) and $T_{e}$ is the time between effectively independent samples. Taking $T_{e}$ as the Markov decorrelation time of the first four sample S-PCs $\left(T_{e} \approx 4.5\right.$ months) yields $n_{\mathrm{eff}} \approx 70$ as a conservative estimate (Metz 1991). To apply M-SSA to the shorter random S-PCs, the window length was reduced correspondingly from 60 to 13 months.

The noise spectrum suggests that eight M-SSA components are significant (Vautard et al. 1992). This is probably a conservative estimate since the noise spectrum cuts the estimated model spectrum above the lat-

\section{(a) Decade I regression}

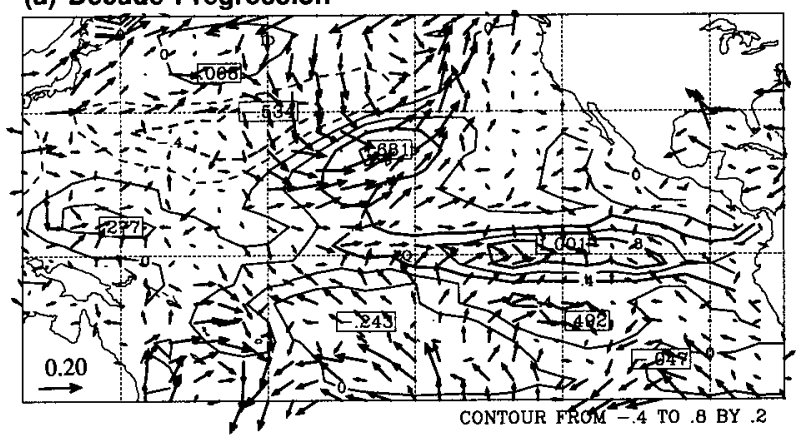

(b) Decade II regression

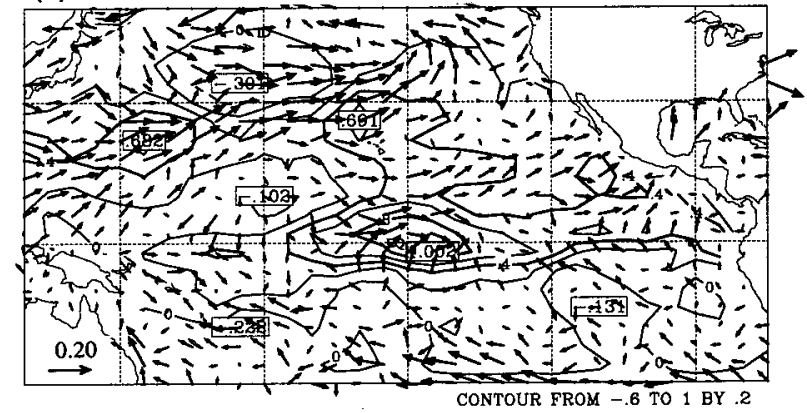

FIG. 15. Regression maps of anomalous SST (contours) and $\tau$ (arrows) with the anomaly index for SST RCs 1-2 in Fig. 10 for (a) decade I and (b) decade II. The mean seasonal cycle was removed and the SST data low-pass filtered to remove periods shorter than 10 months prior to the regression. Anomalies are normalized such that the maximum SST anomaly is $1 \mathrm{~K}$. SST contour interval is $0.2 \mathrm{~K}$, with positive contours solid and negative contours dashed; units of $\tau$ are dyn $\mathrm{cm}^{-2}$, with the standard $\tau$ arrow of $0.2 \mathrm{dyn}^{-2}$ in the lower-left corner of each panel. 


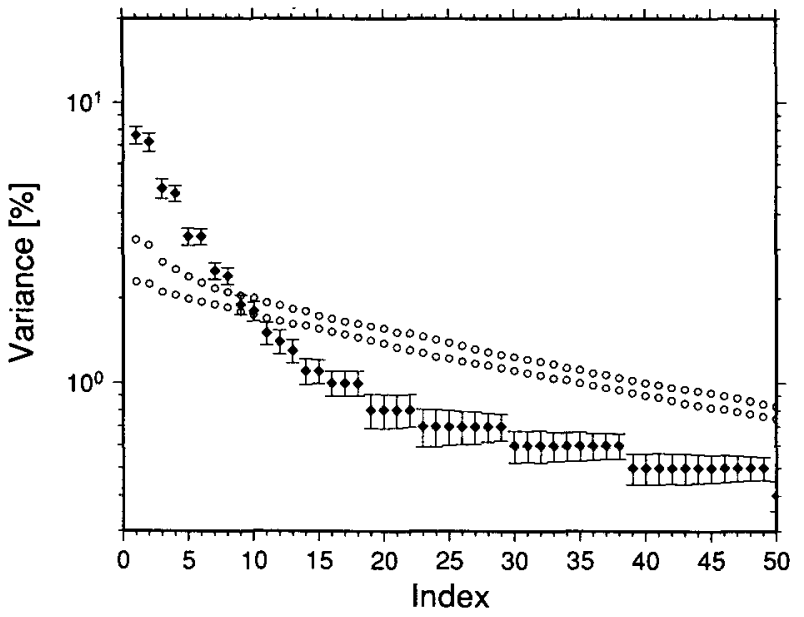

FIG. 16. Eigenvalue spectrum for combined M-SSA of three equatorial fields (SST, $\tau_{x}$, and $20^{\circ} \mathrm{C}$ depth) for 26 -year extension to decade II (diamonds), plus 5- and 95-percentage points of a sample of 100 realizations of red noise (circles). The error bars indicate the $90 \%$ confidence interval, constructed as $\pm 1.96 \sigma_{k}$, where $\sigma_{k}$ is the standard deviation of the respective red-noise eigenvalues.

ter's break in slope (Vautard and Ghil 1989). The two leading PC pairs, together with their MEM spectra, are plotted in Figs. 17 and 18, respectively. The leading modal pair is again an oscillatory mode with a QQ period; its PCs are much nearer to sinusoidal than those of decade II, with MEM spectra sharply peaked near 51 months. The second modal pair-also present in decade II-is episodic and has a broad spectral peak around 20 months. Both leading pairs pass the pairing criteria of Vautard et al. (1992). No QB period is present in the eight significant leading modes, though we note in passing a weak peak at about 9.5 months, which is visible in Fig. 18. Figure 19 shows the RCs of the QQ mode over a 10-year period. They are quite comparable with those of decade II (Fig. 12), but the oscillation is better resolved even though it is weaker in amplitude. The RCs of the 20-month mode (not shown) are very similar in structure.

\section{Conclusions}

This paper complements the seasonal cycle study of Part I by investigating our CGCM's interannual variability in the equatorial Pacific. We have analyzed two 11 -year simulations ("decades" I and II), only differing in 1 ) the initial states and 2) the treatment of the surface heat fluxes at low wind speeds and of solar penetration into the ocean. These relatively minor changes in the parameterization of physical processes cause the mean state and seasonal cycle of decade II-the subject of Part I-to be slightly more realistic, with a stronger east-west gradient of SST at the equator and stronger surface winds.

Multichannel singular spectrum analysis (M-SSA) was used to extract the periodic components of inter-
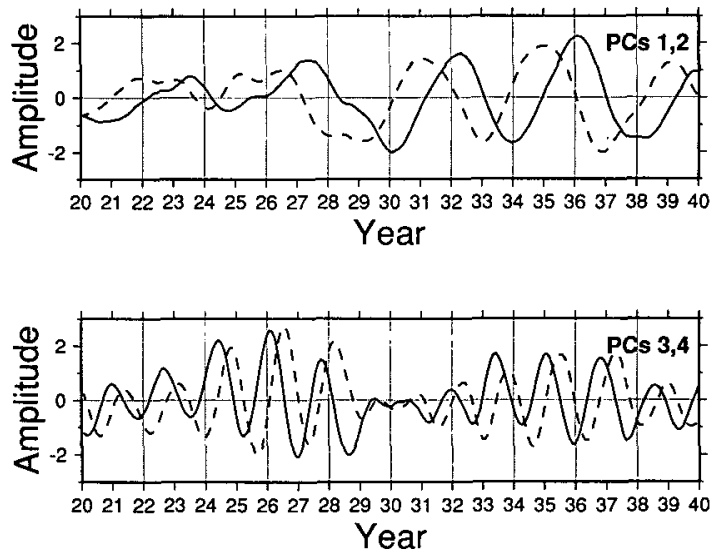

FIG. 17. Normalized PCs $1-4$ of combined M-SSA for 26-year extension to decade II.

annual variability. M-SSA permits a unified comparison with the model's annual and semiannual modes analyzed in Part I. The technique did isolate two vigorous low-frequency near periodicities in the simulated time series that are approximate subharmonics of the annual cycle: a quasi-biennial (QB $\sim 27$ months) mode in decade I and a quasi-quadrennial $(\mathrm{QQ} \sim 48$
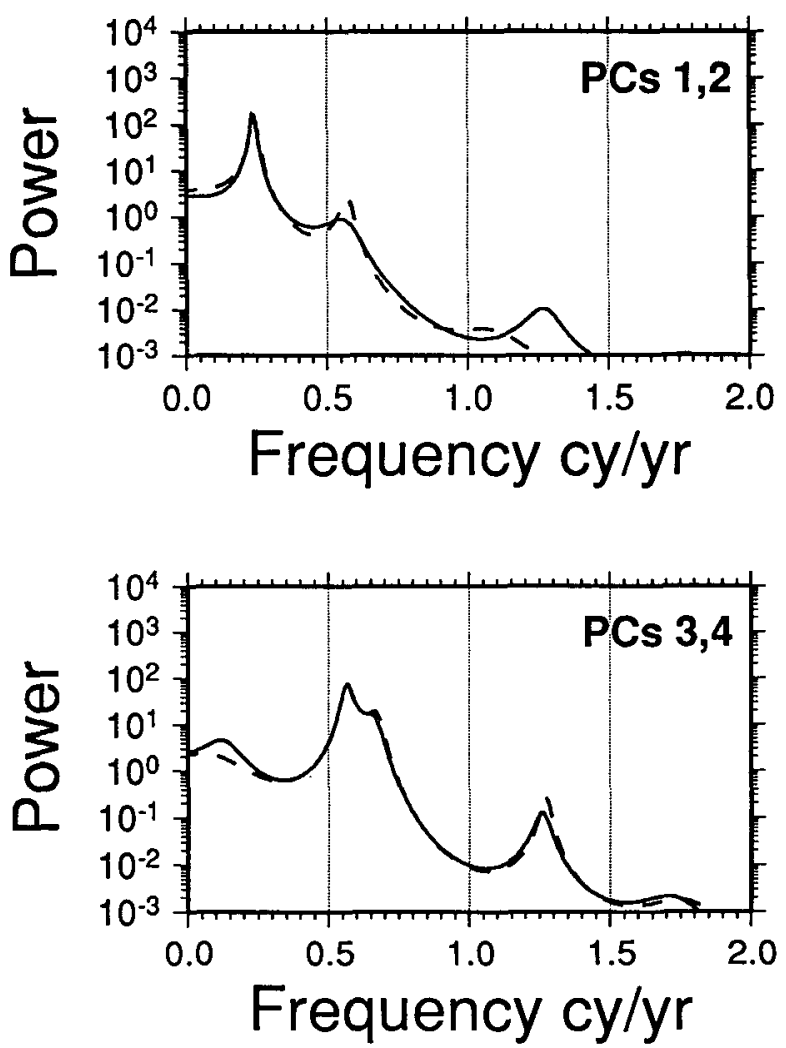

FJG. 18. MEM spectra (30 poles, 1000 frequency intervals) for PCs 1-4 in Fig. 17. 
(a) SST RCs

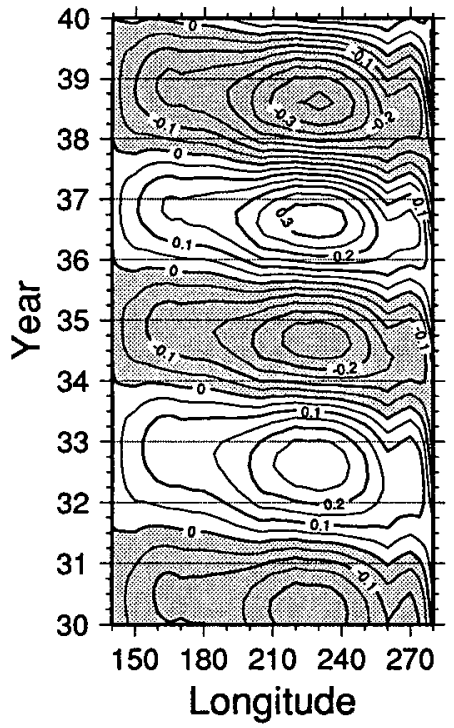

(b) $\tau_{\mathrm{X}} \mathrm{RCs}$

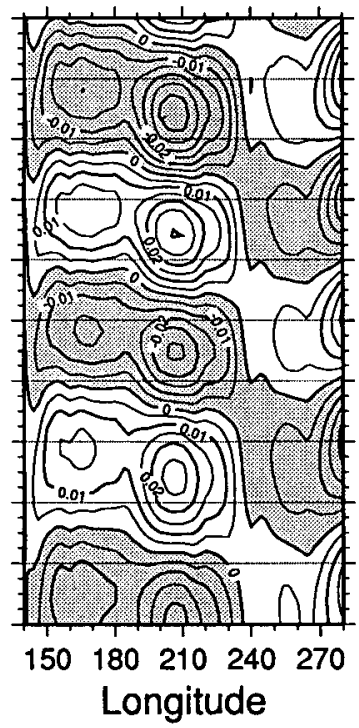

(c) $200 \mathrm{C} \mathrm{RCs}$

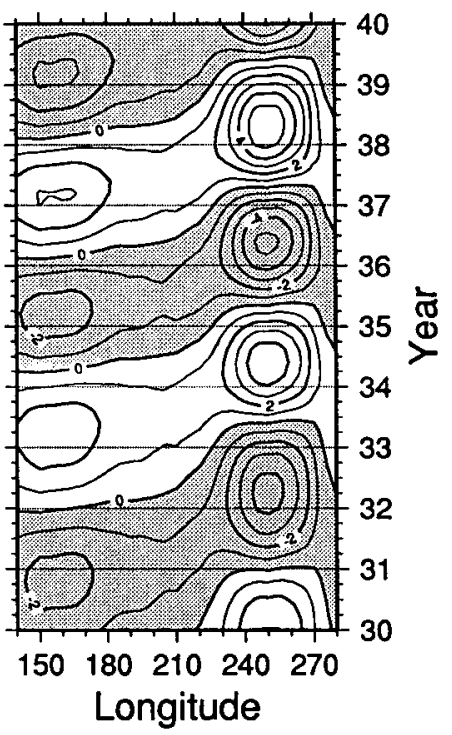

FIG. 19. RCs 1-2 for 26-year extension to decade II: (a) SST $(0.05 \mathrm{~K})$, (b) $\tau_{x}\left(0.005 \mathrm{dyn} \mathrm{cm}^{-2}\right)$, and $(\mathrm{c})$ depth of $20^{\circ} \mathrm{C}$ isotherm-negative deeper $(1 \mathrm{~m})$. Negative anomalies are stippled.

months) mode in decade II, with variances $33.6 \%$ and $22.3 \%$ of the respective SST totals. Both periods are very close to those identified in COADS data (Jiang et al. 1992). Although decade II is undesirably short compared with the QQ period, an additional 26 years of simulation confirmed the results. The associated modal structures are characterized by predominantly standing oscillations in SST that peak in the eastern Pacific, accompanied by almost simultaneous zonal wind-stress anomalies that peak to the west of the SST anomaly. The zonal phase shift between the two fields, however, is less than observed; we speculate that this may be associated with the underestimated mean SST gradient in the central Pacific and even the underestimation of absolute equatorial SST by the model.

Anomaly magnitudes of SST are underestimated by a factor of 2 , and those of zonal wind stress by a factor of 4 . Thus-as in the annual cycle (Part I) - the model's ratio of stress to SST anomalies reaches only half its observed magnitude. Nevertheless, this ratio (about 0.1 and 0.2 dyn $\mathrm{cm}^{-2} \mathrm{~K}^{-1}$ for model and observations, respectively) is about four times larger than that of the annual cycle $\left(\sim 0.025\right.$ and 0.5 dyn $\mathrm{cm}^{-2} \mathrm{~K}^{-1}$, respectively; Part I). This larger ratio is consistent with its being a measure of coupling strength (Neelin 1990) and points to the coupled character of the interannual modes and the primarily forced nature of the annual mode. We recall that the semiannual mode lies in between but closer to the free modes (Part I). The corresponding ratios of thermocline depth to SST anomalies have similar magnitudes for the interannual and annual modes.

Thermocline-depth anomalies peak in the model near the eastern edge of the basin ahead of SST and are small in the west Pacific. Nevertheless, there is a phase shift of about $90^{\circ}$ across the basin, with anomalies in the west leading those in the east; a shift of $180^{\circ}$ would characterize an ocean in equilibrium with periodic wind-stress variation. This subsurface memory of the thermocline to past wind stress, together with the zonal phase difference between SST and $\tau_{x}$, is the hallmark of ENSO. The weakness of the model's thermocline anomalies in the west Pacific is less realistic but consistent with the overly eastward location of the simulated $\tau_{x}$ anomalies. The theoretical work of Jin and Neelin (1993) suggests that our CGCM's oscillations belong to the category of "mixed SST-subsurface dynamics modes." The slight westward propagation of the SST patterns is consistent with this description.

The structures of the QB and QQ modes bear a family resemblance with the "forced" annual and semiannual modes of Part I. The SST-signatures of all of the modes peak in the eastern part of the basin in the region of mean upwelling, with the seasonal cycle modes peaking near the coast. The annual mode stands out as primarily forced, with wind-stress anomalies leading those of SST by about a one-quarter period at the eastern edge of the basin (Part I). Both low-frequency modes - together with the semiannual modehave the character of free coupled modes, with the zonal wind stress almost temporally in phase with SST. Thermocline anomalies in the west lead those in the east in both the low-frequency and annual modes, with the subsurface anomaly peaking ahead of SST in the east Pacific.

Interestingly, the QB and QQ modes appear to ex- 
clude each other in the CGCM simulations examined. Although decade I is too short to conclude that the QB mode is typical of the coupled GCM, the 26-year extension to decade II corroborates the QQ mode, together with the broad 18-20-month mode. Jin and Neelin (1993) have recently linked the character of equatorial interannual variability occurring in a simplified model, that is, its inherent periods and spatiotemporal structures, to a set of fundamental model parameters. The latter include the effective coupling strength between atmosphere and ocean, the relative importance of subsurface dynamical processes and frictionally driven advection and upwelling in the surface layer, as well as the form of the atmospheric surface wind response to a given SST distribution. Neelin et al. (1992, 1994) and Jin and Neelin (1993) suggest that the spectrum of results obtained in coupled general circulation model (GCM) studies can be reconciled in terms of each GCM's particular location in the space spanned by an analogous set of fundamental parameters, whereby the value of a simplified model parameter, such as "coupling strength," clearly has a nontrivial expression in terms of the various physical parameterizations in the coupled GCM. The obvious interpretation is that our CGCM may simply be located at different positions in this parameter space in each simulation. Although the climate "basic state" does not change dramatically, decade II has a stronger zonal gradient of SST at the equator, with the cold tongue being more intense and the extreme west Pacific being warmer. This is associated with slightly stronger mean equatorial wind stress. Thus, the mean climate of decade II is more realistic than that of decade I, and this is consistent with the dominance of the more vigorous QQ mode, which is the most energetic component of ENSO (Jiang et al. 1992).

To what extent could differing initial states in the two simulations be responsible for selecting different dominant modes of variability? Lorenz (1990) has suggested that interannual variability in the atmosphere might arise from the coexistence of separate limit cycles at constant insolation during one season and their random selection by chaotic evolution during the complementary season. A similar situation might prevail on interannual timescales in the coupled system, with the choice of QB and QQ variability due to slight changes in oceanic or atmospheric initial state. The evanescence of the QB and QQ modes in decades I and II, respectively, is suggestive of adjustment responses of the CGCM to an initial imbalance: in the first simulation (the QB mode) to an ocean at rest, and in the second (QQ) to changes in model parameterizations. An uncoupled simulation of the AGCM forced with observed SSTs substantially underestimates equatorial wind-stress anomalies, suggesting that the simulated atmosphere-ocean coupling processes in our coupled GCM might be subcritical with respect to Neelin et al.'s (1994) first oscillatory bifurcation.
Many questions remain regarding the nature of the simulated modes. The QB and QQ modes may be separate bifurcations of the same mean state or seasonal cycle. The QQ mode may result from period doubling of the QB mode. Both modes may be entrained by the annual cycle to be subharmonics of it. Jin et al. (1994) introduced the seasonal cycle into the Neelin-Jin (Neelin 1991; Jin and Neelin 1993) simplified model and studied its stability theoretically and numerically. They showed that finite-amplitude periodic solutions with periods of exactly $1,2,3,4$, and $5 \mathrm{yr}$ are obtained, depending on the value of the control parameters mentioned above, as part of a "devil's staircase." In this scenario, the broadest "step" of the staircase (Fig. 1b of Jin et al. 1994) is the 4-year step, explaining the dominance of the QQ peak in both the COADS data (Jiang et al. 1992) and the extended run starting with decade II and exhibiting the more realistic mean state and seasonal cycle in our CGCM. The dominance of the QB peak in decade I can then be associated with less realistic parameter values and frequency locking to the 2-year step of the staircase. The longer periods associated with both the QQ (48-52 months in CGCM and COADS data, rather than 48) and QB (26-28 months in model and data) modes are simply due to the intermittent character of the respective oscillations: the spells of small amplitude translate into a longer average period in any spectral-analysis method. Decade I is too short in this interpretation for the QB mode to recover from its initial decay. The extended QQ-dominated run has the mode undergoing large- and smallamplitude episodes, similar to those of the observed intraseasonal oscillations in Ghil and Mo (1991a,b), as studied with the AGCM used here by Marcus et al. (1994). The complete devil's staircase scenario calls for successively smaller peaks associated with the 4year step, at 2 and $4 / 3$ years. Both a QB and a 15-16month peak are present in the COADS data (Jiang et al. 1992). The smaller and broader 18-20-month peak here seems to be the merged version of these two peaks due to insufficient length of even the extended run. To complete the study of all three modes-QQ, QB, and 16-month-in the observations (Jiang et al. 1992) and CGCMs (present paper), it will be necessary to explore fully the phase-parameter space of interannual climate variability with the aid of simple and intermediate models (Ghil et al. 1991; Neelin et al. 1994), as well as to study much longer runs.

Acknowledgments. It is a pleasure to thank Y. Chao, F.-F. Jin, M. Latif, E. N. Lorenz, J. D. Neelin, and S. G. H. Philander for helpful discussions. We are grateful to J. Spahr for computing support and to N. Jiang and C. Penland for some of their computer programs. This work was supported by NSF and DARPA under Cooperative Agreement NCR-8919038 with CNRI (AWR, CCM and CRM), by INCOR and "T-POP" (AWR), and by an NSF Special Creativity 
Award (MG). The model integrations were performed at the San Diego Supercomputer Center. The development of the model was partially supported by ONR Grant N00014-89J-1845.

\section{REFERENCES}

Allen, M. R., P. L. Read, and L. A. Smith, 1992a: Temperature timeseries? Nature, 355, 686.

,$--\frac{}{-}$, and $1992 \mathrm{~b}$ : Temperature oscillations. Nature, 359, 679.

Battisti, D. S., and A. C. Hirst, 1989: Interannual variability in the tropical atmosphere-ocean system: Influence of the basic state and ocean geometry. J. Atmos. Sci., 46, 1687-1712.

Bjerknes, J., 1969: Atmospheric teleconnections from the equatorial Pacific. Mon. Wea. Rev., 97, 163-172.

Broomhead, D. S., and G. P. King, 1986: Extracting qualitative dynamics from experimental data. Physica $D, 20,217-236$.

Burg, J. P., 1967: Modern spectral analysis. 37th Annual Meeting of the Society of Exploration Geophysicists, Oklahoma City, OK, Society of Exploration Geophysicists. (1978: reprint in Modern Spectral Analysis. D. G. Childers, Ed., IEEE Press, 34-41.)

Cane, M. A., 1979: The response of an equatorial ocean to simple wind stress patterns: II. Numerical results. J. Mar. Res., 37, 253-299.

- and E. S. Sarachik, 1981: The response of a linear baroclinic equatorial ocean to periodic forcing. J. Mar. Res., 39, 651-693.

Chao, Y., and S. G. H. Philander, 1993: On the structure of the Southern Oscillation. J. Climate, 6, 450-469.

Ghil, M., and K. Mo, 1991a: Intraseasonal oscillations in the global atmosphere. Part I: Northern Hemisphere and tropics. J. Atmos. Sci., 48, 752-779.

$\longrightarrow$, and $-1991 \mathrm{~b}$ : Intraseasonal oscillations in the global atmosphere. Part II: Southern Hemisphere. J. Atmos. Sci., 48, $780-790$.

- and R. Vautard, 1991: Interdecadal oscillations and the warming trend in global temperature time series. Nature, 350, 324.

_, M. Kimoto, and J. D. Neelin, 1991: Nonlinear dynamics and predictability in the atmospheric sciences. U.S. National Report to the International Union of Geodesy and Geophysics $1987-$ 1990, Rev. Geophys., Suppl. 46-55.

Gill, A. E., 1980: Some simple solutions for heat induced tropical circulation. Quart. J. Roy. Meteor. Soc, 106, 447-462.

Hirst, A. C., 1986: Unstable and damped equatorial modes in simple coupled ocean-atmosphere models. J. Atmos. Sci., 43, 606630.

Jiang, N., J. D. Neelin, and M. Ghil, 1992: Quasi-quadrennial and quasi-biennial variability in COADS equatorial Pacific sea-surface temperature and surface zonal winds. Proc. 17th Climate Diagnostics Workshop, Norman, OK, Climate Analysis Center, National Oceanic and Atmospheric Administration,

Jin, F.-F., and J. D. Neelin, 1993: Modes of interannual tropical ocean-atmosphere interaction-A unified view. Part I: Numerical results. J. Atmos. Sci., 50, 3477-3503.

- - - , and M. Ghil, 1994: El Niño on the devil's staircase: Annual subharmonic steps to chaos. Science, 264, 70-72.

Keppenne, C. L., and M. Ghil, 1992: Adaptive filtering and prediction of the Southern Oscillation index. J. Geophys. Res., 97(20), 449-454.

Kitoh, A., 1991: Interannual variations in an atmospheric GCM forced by the 1970-89 SST. Part I: Response of the tropical atmosphere. J. Meteor. Soc. Japan, 69, 251-269.

Levitus, S., 1982: Climatological atlas of the world ocean. NOAA Professional Paper No. 13, 173 pp., 17 microfiche.

Lorenz, E. N., 1990: Can chaos and intransitivity lead to interannual variability? Tellus, 42A, 378-389.
Marcus, S. L., M. Ghil, and J. O. Dickey, 1994: The extratropical 40-day oscillation in the UCLA general circulation model. Part I: Atmospheric angular momentum. J. Atmos. Sci., 51, 14311446.

Metz, W., 1991: Optimal relationship of large-scale flow patterns and the barotropic feedback due to high-frequency eddies. J. Atmos. Sci., 48, 1141-1159.

Meyers, G., 1979: Annual variation in the slope of the $14^{\circ} \mathrm{C}$ isotherm along the equator in the Pacific ocean. J. Phys. Oceanogr., 9, $885-891$.

Nagai, T., T. Tokioka, M. Endoh, and Y. Kitamura, 1992: El Niño/ Southern Oscillation simulated in an MRI atmosphere-ocean coupled general circulation model. J. Climate, 5, 1202-1233.

Neelin, J. D., 1990: A hybrid coupled general circulation model for El Niño studies. J. Atmos. Sci., 47, 674-693.

, 1991: The slow sea surface temperature mode and the fastwave limit: Analytic theory for tropical interannual oscillations and experiments in a hybrid coupled model. J. Atmos. Sci., 48, 584-606.

, and I. M. Held, 1987: Modeling tropical convergence based on the moist static energy budget. Mon. Wea. Rev., 115, 3-12. , M. Latif, M. A. F. Allaart, M. A. Cane, U. Cubasch, W. L. Gates, P. R. Gent, M. Ghil, C. Gordon, N. C. Lau, C. R. Mechoso, G. A. Meehl, J. M. Oberhuber, S. G. H. Philander, P. S. Schopf, K. R. Sperber, A. Sterl, T. Tokioka, J. Tribbia, and S. E. Zebiak, 1992: Tropical air-sea interaction in general circulation models. Climate Dyn., 7, 73-104.

- , F.-F. Jin, and M. Latif, 1994: Dynamics of coupled oceanatmosphere models: The tropical problem. Ann. Rev. Fluid Mech., 26, 617-659.

Paulson, E. A., and J. J. Simpson, 1977: Irradiance measurements in the upper oceans. J. Phys. Oceanogr., 7, 952-956.

Penland, C., M. Ghil, and K. M. Weickmann, 1991: Adaptive filtering and maximum entropy spectra with application to changes in atmospheric angular momentum. J. Geophys. Res., 96, D12, 22 659-22 671.

Philander, S. G. H., R. C. Pacanowski, N.-C. Lau, and M. J. Nath, 1992: Simulation of ENSO with a global atmospheric GCM coupled to a high-resolution tropical Pacific ocean GCM. J. Climate, 5, 308-329.

Press, W. H., B. P. Flannery, S. A. Teukolsky, and W. T. Vetterling, 1986: Numerical Recipes, The Art of Scientific Computing. Cambridge University Press, 818 pp.

Rasmusson, E. M., X. Wang, and C. F. Ropelewski, 1990: The biennial component of ENSO variability. J. Mar. Syst., 1, 71-96.

Robertson, A. W., C.-C. Ma, C. R. Mechoso, and M. Ghil, 1992: Simulation of the tropical Pacific climate with the UCLA coupled GCM. Proc. 17th Climate Diagnostics Workshop, Norman, OK, Climate Analysis Center, National Oceanic and Atmospheric Administration.

$\longrightarrow,-,-$ and -1995 : Simulation of the tropical Pacific climate with a coupled ocean-atmosphere general circulation model. Part I: The seasonal cycle. J. Climate, 8, 1178-1198.

Stricherz, J. N., J. J. O'Brien, and D. M. Legler, 1992: Atlas of Florida State University Tropical Pacific winds for TOGA 1966-1985. Mesoscale Air-Sea Interaction Group Technical Report, Florida State University.

Vautard, R., and M. Ghil, 1989: Singular spectrum analysis in nonlinear dynamics with applications to paleoclimatic time series. Physica D, 35, 395-424.

- - P. Yiou, and M. Ghil, 1992: Singular-spectrum analysis: A toolkit for short, noisy chaotic signals. Physica $D, \mathbf{5 8}, 95-126$.

von Storch, H., T. Bruns, I. Fischer-Bruns, and K. Hasselmann, 1988: Principal Oscillation Pattern analysis of the 30 to 60 day oscillation in a GCM. J. Geophys. Res., 93, 11 022-11 036. 